\title{
Optimal Planning and Operation of Multi-Vector Energy Networks: A Systematic Review
}

\author{
Hosseini, S.H.R. ${ }^{1,}{ }^{*}$, Allahham, A. ${ }^{1}$, Walker, S.L. ${ }^{1}$, Taylor, P. ${ }^{1,2}$ \\ $1=$ School of Engineering, Newcastle University, Newcastle upon Tyne, NE1 7RU, United Kingdom \\ 2= Faculty of Engineering, University of Bristol, Bristol BS8 1QU, UK \\ *=corresponding author details hamid.hosseini@newcastle.ac.uk
}

\begin{abstract}
This paper provides a systematic review of recent publications on simulation and analysis of integrated multi-vector energy networks and carries this out through the lens of energy trilemma. This review is essential for energy research community to move forward in effective manner toward 2050 net zero carbon targets. This paper presents a holistic view of state-of-the-art of research in this field and identifies gaps in knowledge which should be addressed by future research urgently. Furthermore, this paper introduces a taxonomy of energy networks analysis, offering a unified description of findings of relatively large number of publications devoted to the subject. Moreover, this work analyses and classifies current research trends in field of analysis of energy networks integration, and also identifies future trends in this field. This review serves as a guide to researchers regarding the main findings of energy networks integration evaluated through the lens of energy trilemma. The research papers have been classified into three groups: (i) Operational analysis; (ii) Optimal dispatch; (iii) Optimal planning. The focus of the paper is energy networks, since they play fundamental role in integrated energy systems and there is a lack of understanding of interactions and interdependencies between multi-vector networks. Also, focus of this paper has been on key findings of published research rather than details of individual energy models. The paper provides useful insights for energy research community by presenting several novel ideas for future research and facilitating the path to a decarbonised economy, due to the fulfilled comprehensive systematic review.
\end{abstract}

\section{Highlights}

- A total of 186 most recent papers on integrated multi-vector energy networks analysis are systematically reviewed.

- Findings of those papers were classified into three groups: operational analysis, optimal dispatch and planning.

- In each group, different aspects of the three elements of energy trilemma were evaluated in detail.

- Several recommendations for future applied research priorities are presented.

- Useful insights for the energy research community are provided to facilitate the path to a decarbonised economy.

- Integrated operation of the networks has economic and environmental benefits (e.g. $f 35 \mathrm{M}$ cost saving and 250 kton carbon saving (per month) by introduction of power-to-gas in the British gas and electricity transmission network), which depends on several factors, including the scale of the networks, the load profile condition, the capacity and number of available coupling components and storage devices. 
Keywords: systematic review, operational analysis, optimal dispatch, optimal planning, integrated multi-vector energy networks

\author{
Abbreviations \\ Al: Artificial Intelligence \\ CAPEX: Capital Expenditure \\ CHP: Combined Heat and Power \\ DHN: District Heating Network \\ DR: Demand Response \\ GB: Gas Boiler \\ GHG: Greenhouse Gas \\ HP: Heat Pump \\ ICT: Information and Communication Technologies \\ IEN: Integrated Energy Networks \\ IES: Integrated Energy System \\ IoT: Internet of Things \\ $M L:$ Machine Learning \\ NGPP: Natural Gas-fired Power Plants \\ NPV: Net Present Value \\ OPEX: Operational Expenditure \\ P2G: Power-to-Gas \\ RES: Renewable Energy Resources \\ TEE: Techno-Economic-Environmental \\ TSO: Transmission System Operator
}

\title{
1. Introduction
}

The international aspiration to reach net zero carbon in energy systems by 2050 is growing. In the UK, the government has set a target of 'Net Zero' Greenhouse Gas (GHG) emissions by 2050 in order to reduce contribution to global warming [1]. This necessitates performing energy evaluation through a system-of-systems approach, in order to understand the intrinsic properties of the main layer/sections of the Integrated Energy Systems (IES), from natural resources and distribution to the final energy user as well as the interactions and interdependencies within each layer/section [2]. These interdependencies and interactions occur between different energy vectors including natural gas, electricity, cooling and heating. Energy networks are key components of the whole energy system that connect the natural resources and transport them to the final energy user. Therefore, there is a growing consensus that there is a need for a step change in research and development in multi-energy networks and their interdependencies in order to facilitate the path to achieving the carbon reduction targets.

Energy networks (including gas, electricity and district heating/cooling networks) are still predominantly planned and operated separately. However, there are several drivers for integrated planning and operation of energy networks including reduction of the use of primary energy, increasing integration of Renewable Energy Resources (RESs) and facilitating a low carbon economy [3]. The synergies between energy networks $[4,5]$ and the interdependencies and interactions between these networks have been shown to have the potential to bring several benefits to the integrated planning, optimal dispatch and operation of energy networks including increasing energy conversion efficiency, maximised utilisation of primary energy sources, improving the energy system 
flexibility, resilience and security and carbon emission reduction $[3,6,7]$. Modelling of IES is crucial for understanding the energy networks and the potential benefits of their integrated operation. Several energy system models have been developed, which have been presented and discussed in the literature $[3,6,8,9]$. Moreover, Information and Communication Technologies (ICTs) have a substantial role in integrated energy systems since they support the coordinated operation of the system by integrating different parts of the energy system through information sharing frameworks [7]. Consequently, there are several complexities associated with planning, management and operation of integrated energy networks, which needs close collaboration of several fields of expertise including computing science and several engineering disciplines to address the challenges of this multi-disciplinary field of knowledge.

An overview of the benefits of integrated operation of energy networks has been carried out in [3]. However, this does not include a significant amount of detail and does not relate the findings to the internationally accepted concept of the energy trilemma, i.e. flexibility, security and affordability. This greater detail and link to the trilemma is required in order to identify gaps and directions for an appropriate future research for meeting carbon reduction targets. To the best of the knowledge of the authors, no other comprehensive or systematic reviews were found, that have linked together and organised the findings of the most important literature on the analysis of energy networks in relation to the energy trilemma.

Slightly different definitions of the three elements of the energy trilemma exist. Based on the frequency of the definitions used by the authors of the reviewed papers, the following most common definitions of the energy trilemma have been used in this paper:

(i) Flexibility of operation:

This element of the trilemma denotes how much Integrated Energy Networks (IENs) can respond to any change in the coupled network(s), including the increase in demand, without violation of the operational conditions or technical limits.

(ii) Security of supply:

This element of the trilemma indicates the extent that one network vector can support (in terms of meeting the demand) the operation of other different but coupled network vectors in the case of a fault occurrence in part of those coupled network(s), or a shortage of supply in those coupled network(s).

(iii) Affordability:

This element of the trilemma denotes the amount of costs associated with the operation, dispatch or planning of the IENs. These costs include operational and maintenance costs as well as the cost of purchase and deployment of new assets.

It should be noted that although environmental sustainability (as an indication of the environmental performance of IENs) has not been explicitly considered in this definition of the energy trilemma, any changes to the planning or operation of IENs will affect their impact on the environment. In this paper, the environmental impact of any variation in the above energy trilemma elements are also investigated and evaluated. It should be noted that the aforementioned definition of the energy trilemma is in line with the goal number 7 ('affordable and clean energy') of Sustainable Development Goals. This goal aims to ensure access to affordable, reliable, sustainable and modern energy for all.

Several vectors are incorporated in multi-vector IENs including natural gas, electricity, heating, cooling and hydrogen. Table 1 shows the possible coupling components between the vectors that were frequently investigated in the literature, i.e. gas, electricity and heat. As can be seen from the table, almost all these vectors, i.e. gas, electricity and heat, can be converted into another vector and vice versa. This also shows that these networks can impact the operation of the coupled 
network(s). For example, the electricity network can impact the operation of the gas network: (i) either through electricity to gas conversion units (Power-to-Gas (P2G), electrolyser and electric driven gas compressors); or (ii) through gas to electricity conversion units (Combined Heat and Power ( $\mathrm{CHP}$ ) and gas turbine). Therefore, these bring both benefits and challenges to the operation of the IENs in terms of different elements of the energy trilemma as follows:

(i) Flexibility of operation:

Benefits include, optimal scheduling and planning of the networks for minimum costs and carbon emissions, and optimised utilisation of the available assets. Challenges include unexpected potentially negative impact of networks on one another in case of malfunctioning of the coupling components and hence losing some energy and increasing the costs and carbon emissions;

(ii) Security of supply:

Benefits include, availability of any form of energy in any network to meet the unexpected increased demand in the coupled network(s), and mutual support between network(s) in case of faults in some part of them or shortage of supply from upstream or from limited natural resources. Challenges include: (a) the placement of the coupling components to ensure the security of supply; and (b) networks may not be able to support the coupled network(s) in case of malfunctioning of the available coupling components;

(iii) Affordability:

Benefits include, reduction of costs either through capturing and converting renewable energy via different coupling components into any of the coupled networks, or through optimised utilisation of available assets. Challenges include increase in costs due to load shedding or due to malfunctioning of the coupling components.

There are economic and environmental benefits associated with integrated operation of the networks through these coupling components. As an example, it was shown that introduction of Power-to-Gas (P2G) in the national gas and electricity transmission networks of Great Britain had reduced the costs by $f 35 \mathrm{M}$ and reduced the carbon emissions by 250 kton during a month [56]. However, it should be noted that these figures cannot be generalised and it depends on several factors, including the scale of the networks, the load profile condition (summer or winter), the capacity and number of available coupling components and storage devices.

In order to integrate the networks, through utilising the coupling components listed in Table 1, the following technical interventions are required: sizing and operating the coupling components optimally. Operating the coupling components also requires the data acquisition system, and associated data, to be shared with the control room(s) of different network vectors. This challenging intervention will be discussed in Section 4. Also, among the technologies that are presented in Table 1 , the ones that are underrepresented in this paper, can be considered as potential areas for further work.

Table 1 Points of impact (conversion) of various vectors into one another in multi-vector IENs

\begin{tabular}{|c|c|c|c|c|}
\hline & & \multicolumn{3}{|c|}{ Vector of energy source } \\
\hline & & Gas & Electricity & Heat \\
\hline \multirow{3}{*}{$\begin{array}{l}\text { Vector of } \\
\text { destination } \\
\text { (after } \\
\text { conversion) }\end{array}$} & Gas & & $\begin{array}{c}\text { Power-to-Gas } \\
\text { Electrolyser } \\
\text { Electric-driven gas } \\
\text { compressor }\end{array}$ & N/A* \\
\hline & Electricity & $\begin{array}{c}\text { Gas turbine } \\
\text { CHP }\end{array}$ & & $\begin{array}{l}\text { Heat for steam } \\
\text { turbine }\end{array}$ \\
\hline & Heat & $\begin{array}{c}\text { Gas boiler } \\
\text { CHP }\end{array}$ & $\begin{array}{c}\text { Electric heater } \\
\text { Heat pump }\end{array}$ & \\
\hline
\end{tabular}


*: Not available to the best of the knowledge of the authors

In order to provide guidance for engineers and researchers regarding the operational analysis, optimal dispatch and optimal planning of IENs, the selected articles in the related field published predominantly in the last five years are reviewed. The key findings in these articles are analysed and categorised covering a range of different aspects, which are linked to the aforementioned energy trilemma elements, i.e. flexibility of operation, security of supply, affordability. Additionally, a comprehensive review of the problem formulation and solving algorithms for optimal planning and the optimal dispatch of IEN have been carried out. Consequently, the comprehensive systematic review presented in this paper provides a holistic picture of the state-of-the-art of research in this extensive field and identifies useful insights, directions, and guidelines for valuable future research in pursuit of the low carbon transition.

In this paper the most important findings drawn from the literature, on analysis of energy networks, rather than energy hubs, fall in to the following three categories:

(i) Operational analysis:

This area denotes assessing the operational conditions of the networks and ensuring the networks are meeting the demand without violating the operational limits, i.e. ensuring the voltages in the electricity network, the pressures in the gas network and pressures and temperatures in the District Heating Network (DHN) are all within acceptable and operable ranges. Once, this has been done, a picture of the operation of the networks in terms of the power flows in the electricity network, gas flows in the gas network, and hot water flows in the DHN is obtained. Then, the final step is to evaluate the Techno-Economic-Environmental (TEE) performance of the IEN.

(ii) Optimal dispatch:

Optimal dispatch denotes the optimal operational scheduling of the IENs, which is normally performed for the next few hours. This means in order to meet the demand with the least operational cost (objective function), how much (amount and scheduling) energy from different sources needs to be supplied, or how much the amount and scheduling of different energy conversion units (coupling components) needs to be. Optimal dispatch also considers the operability of the IEN. Additionally, the environmental performance is either considered as an element in the objective function along with the operational cost, or as a constraint. Hence, optimal dispatch performs an optimal TEE operational scheduling of IENs.

(iii) Optimal planning:

Optimal planning denotes planning of all the assets of IENs, including pipes in the gas and district heating networks, cables in the electricity network, generation units in the electricity network, coupling components, for a horizon of time, e.g. next 20 years. In this respect, all the capital and operational costs (mapped to a base year) will be minimised in order for the IEN to meet all the current and future demand subject to being operable and optimally dispatched at all the time snap shots. Similar to optimal dispatch, the environmental performance is either considered in the objective function along with all the costs or as a constraint. Therefore, optimal planning carries out the optimal TEE operational planning of the IEN for meeting the current and future demand.

The papers on energy hubs were not considered since hub level analysis does not consider the operation of the network to ensure the network is physically operable and is able to meet the load without violation of operational constraints (see [203, 204] for review of energy hubs). Also, the focus of this paper is on findings rather than the energy models since the models developed for simulation and analysis of IENs have been reviewed in several other literature $[3,6,8,9]$. 
The structure of the paper is as follows: section 2 explains the methodology adopted and describes the way the publications summarised in this paper were identified. Section 3 describes the most important findings of the papers regarding the elements of energy trilemma and considering the three key categories of operational analysis, optimal dispatch and optimal planning. Section 4 presents several directions for valuable future applied research in optimal planning, optimal dispatch and operational analysis of IENs. Finally, section 5 concludes the insights of the paper.

\section{Methodology}

This section explains the methodology adopted in this paper to find the published researches on analysis of IENs. For this purpose, databases including IEEEXplore, Sciencedirect and Scopus were searched with the following key words in their title or keywords:

- A combination of two of: 'gas', 'heat', 'power'/'electric'

- 'multi-energy', 'multi-vector', 'integrated energy systems', or 'integrated energy networks'

- 'energy system' or 'energy network'

Among the resulting papers the ones based on a model of energy networks, rather than based on a model of energy hubs, were considered since energy hubs are already reviewed in $[203,204]$. Then, an assessment was carried out and hence the papers were filtered further and the ones: (i) with reasonable citations; (ii) from influential researchers in this field; (iii) published in prestigious journals or presented in credible conferences; and (iv) that were rigorous, most interesting and complete, were selected to be reviewed in this paper. Given the fact that English is a universal language, whilst considering only the papers written in English a homogenous cover of the research on analysis of IENs, that is carried out in the world, is captured in this paper. Also, several papers had performed analysis of a single vector (i.e. gas, electricity or heat) as well as the point(s) of connection to the network of other vector(s) and the impact of those networks without considering the operation of those coupled network(s). Those papers were also excluded since the scope of this paper is multi-vector energy networks. In this way, the authors are confident that the most important and influential papers on analysis of energy networks that have been published in the well-known databases have been captured and scanned in this review.

Once the papers were filtered according to the aforementioned eligibility criteria, 186 papers were considered to be reviewed in this paper. Fig. 1 shows that 115 journal papers and 71 conference papers, with majority of 59 IEEE conference papers, were investigated. Fig. 2 illustrates the share of reviewed paper dealing with analysis of IENs. This figure shows the majority of the reviewed papers are published in prestigious journals and conferences. Fig. 3 shows the number of the papers from different countries according to the affiliation of the first author of these papers, which indicates the importance of this topic for different countries around the world. As can be seen, the majority of these papers have been published by the researchers from China (72), UK (31), United States (17) and Iran (12). The rest of the countries have less than 10 publications. 


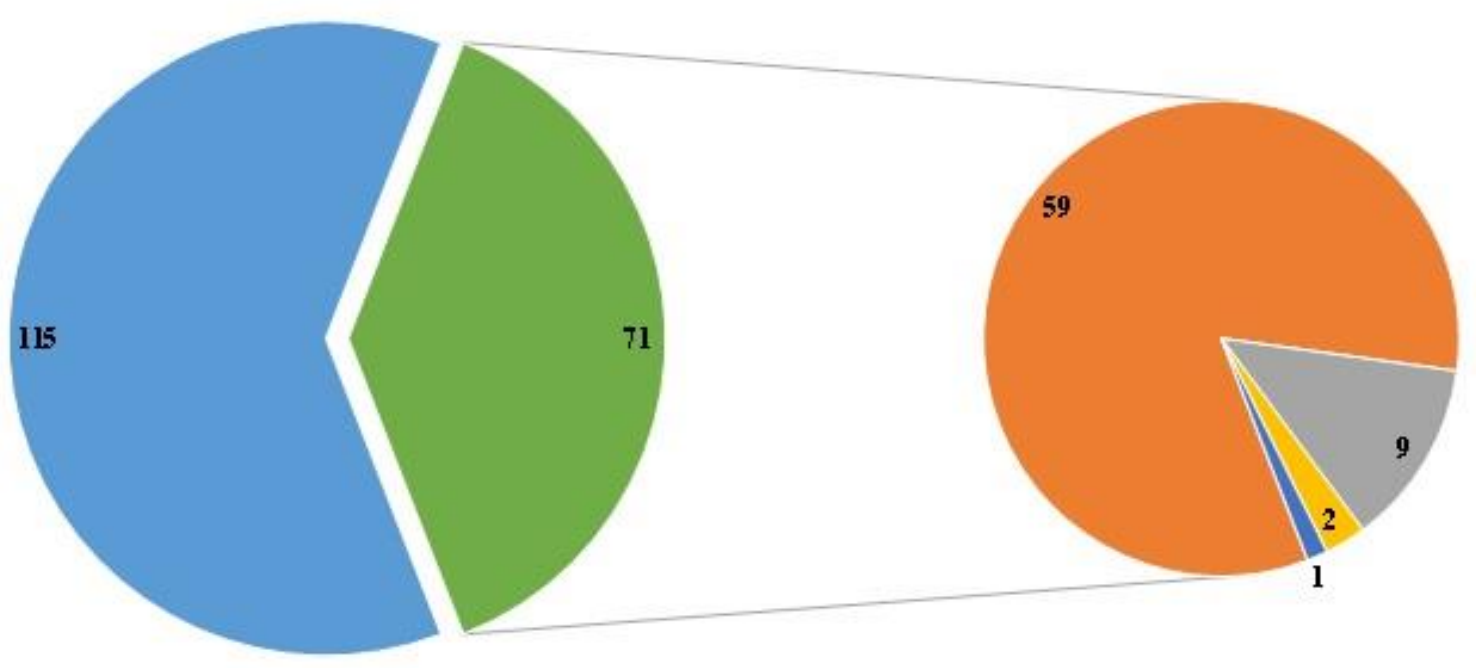

-journal papers = IEEE conferences =Energy Procedia "IET conferences " The Society of Petroleum Engineers

Fig. 1 The type (journal/conference) of the papers reviewed in this paper

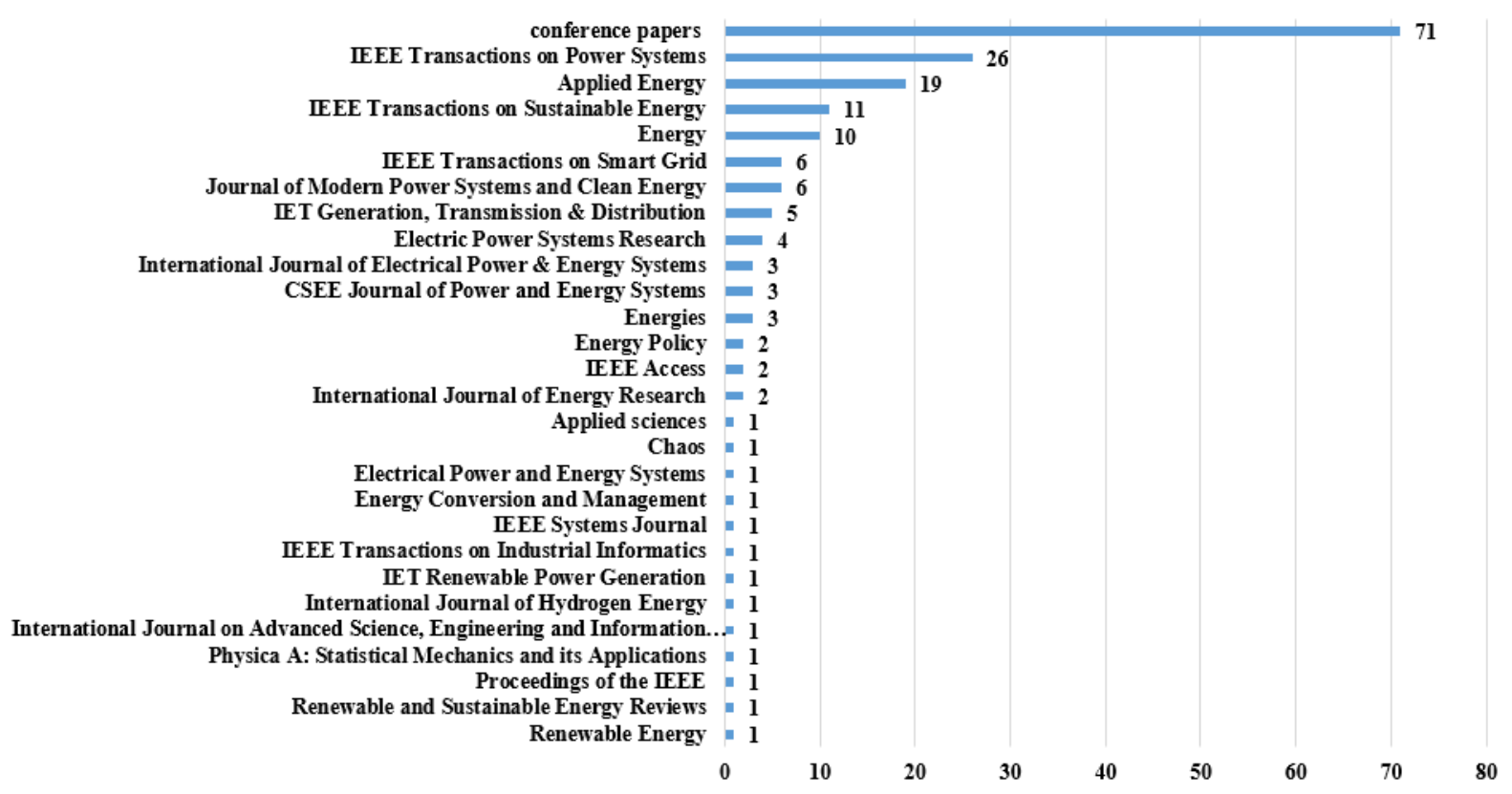

Fig. 2 The share of different publications dealing with analysis of IENs 


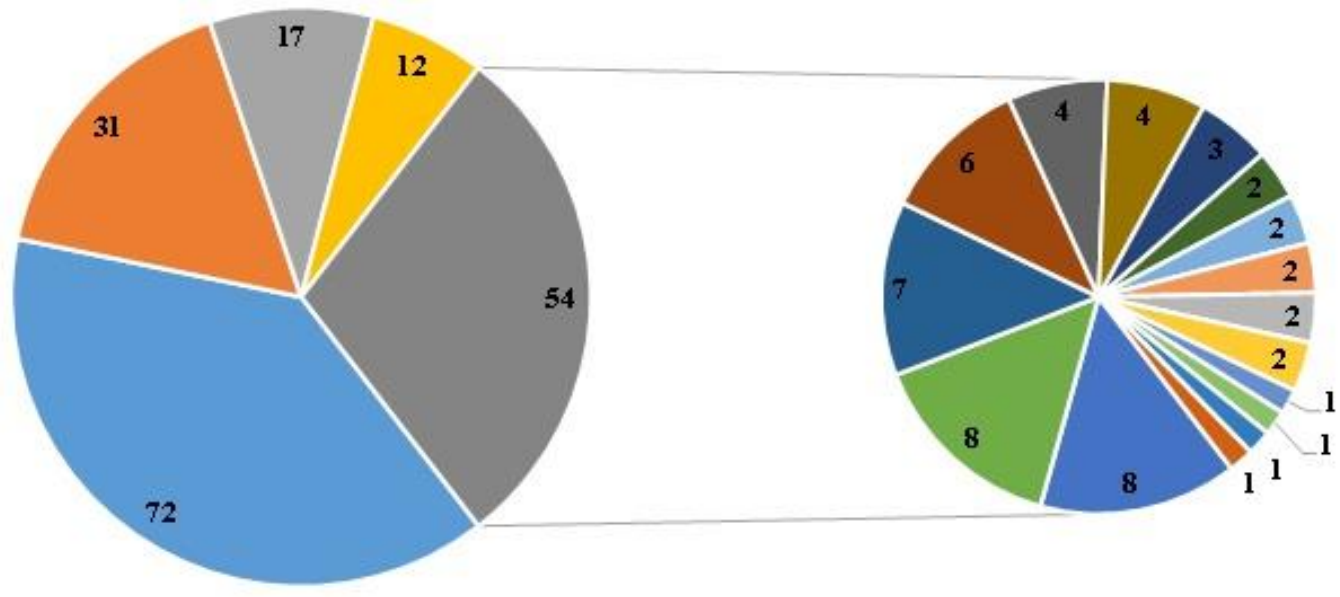

\begin{tabular}{|c|c|c|c|c|c|c|}
\hline - China & = UK & = US & = Iran & = Colomb ia & $=$ Canada & - Australia \\
\hline - Denumark & - Mexico & " Brazil & - Germany & - Sw ifzerland & = Netherlands & = Saudi Arabia \\
\hline Singap ore & Argentina & - France & = Greece & = Indonesia & = Italy & \\
\hline
\end{tabular}

Fig. 3 The number of reviewed papers from different countries based on the affiliation of the first author

These 186 papers were classified into each of the groups below according to their models, research questions and scenarios:

- Papers on operational analysis [12-53]

- Papers on optimal dispatch [54-157]

- Papers on optimal planning [158-200].

As shown above, the geographical coverage of the literature review was diverse and extensive but not exhaustive. However it should be noted that the three categories listed above deal with issues that are applicable to all energy networks regardless of their vector or geographical location and whether they are dealing with legacy networks or new build infrastructure. It is possible that some issues specific to developing countries may not have been identified in this review but these are likely to be driven by commercial or regulatory aspects which are not the focus of this paper which deals with TEE considerations. Therefore, it is reasonable to claim that the findings from this review have global relevance and value.

Fig. 4 shows the number of papers found in the above three groups published in journals and conferences (denoted by 'conf.' in the figure) by year for the last five years. As can be seen from Fig. 4 , the total number of papers published in these three groups has increased in recent years especially for optimal dispatch and optimal planning groups. In these three groups, $82.9 \%, 82.5 \%$, and $80.9 \%$ of the reviewed papers are published in the last five years. 


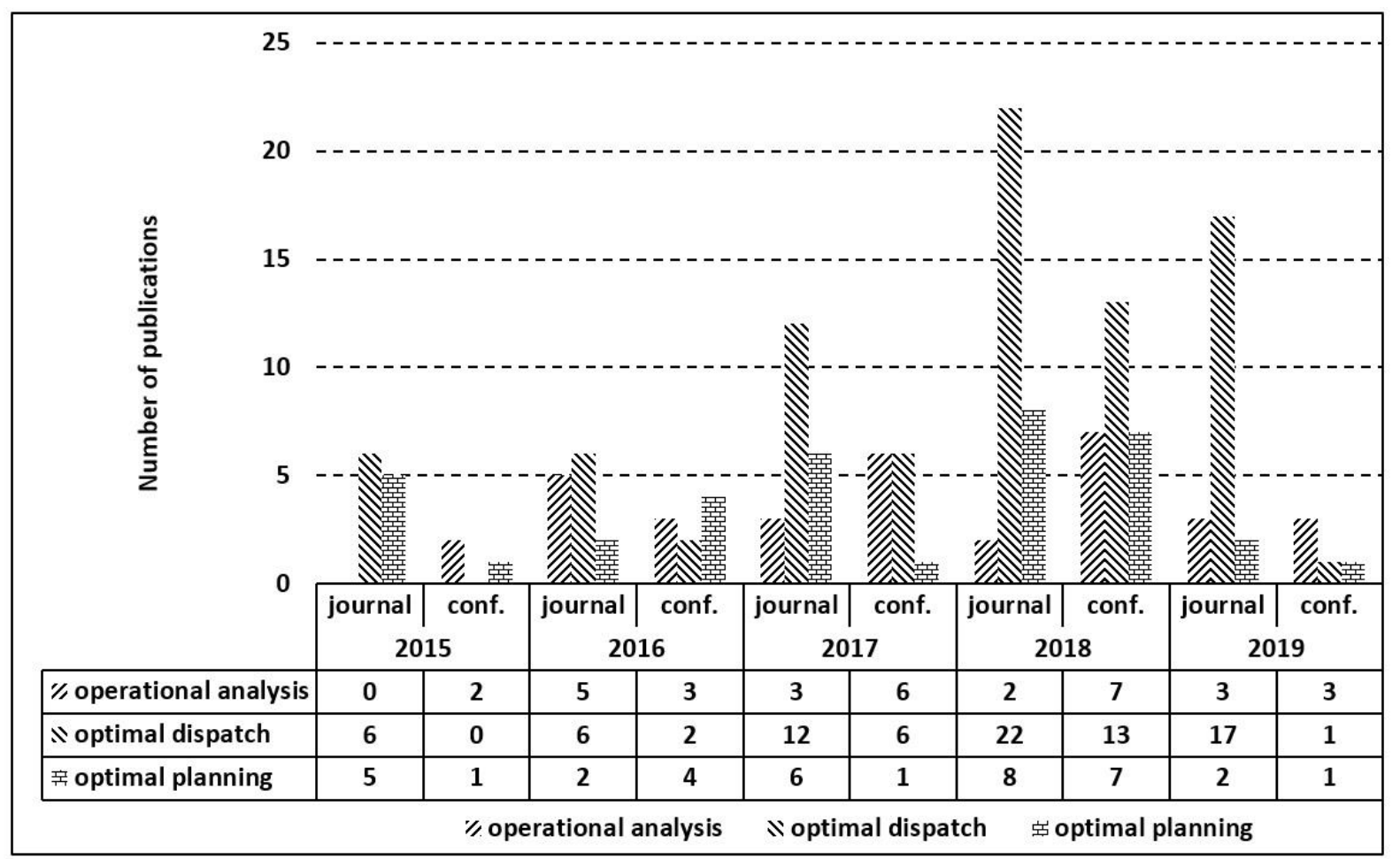

Fig. 4 The number of publications in the last five years on IEN analysis ${ }^{1}$

\section{Classification of IEN analysis methods and key findings}

In this section the methods for IEN analysis adopted in the reviewed papers for operational analysis, optimal dispatch and optimal planning of IENs, the algorithms developed and implemented for formulation and solution of the problem and the key findings of these publications around elements of energy trilemma are presented.

The aspects that were more frequently investigated in the papers are shown in diagrams in Fig. 5 for operational analysis, in Fig. 6 for optimal dispatch and in Fig. 7 for optimal planning of IEN. These aspects were identified based on the keywords of the findings of the papers. All these aspects have impact on analysis of the performance of IEN in terms of the elements of energy trilemma, i.e. flexibility, security and affordability. The proximity of any of the aspects to any of the above elements of energy trilemma in Figs 5-7 does not mean that aspect has more impact on that element of energy trilemma. Also, the darker the arrow connecting the aspect to the whole energy trilemma, the more frequent the appearance and discussion of the aspect in the reviewed papers, as shown by the legend in these figures.

Among these aspects the ones that were discussed more frequently than the others in the papers are described below Figs 5-7 in separate paragraphs. It should be noted that 'Affordability', is included in almost all the paragraphs and hence has not been summarised exclusively in one separate paragraph similar to other elements of energy trilemma.

The references that have validated their developed model by comparing the results of their model with reference data, measurements or a commercial tool without any scenarios or key findings are

\footnotetext{
${ }^{1}$ The latest update of the table was prepared early autumn 2019. Therefore, 2019 is not a full year in the figure.
} 
not explained in the sub-sections of this section, since they have not demonstrated the evolving scenarios to address the energy trilemma. Also, the results and findings of the papers that are not cited in the 'Key findings' sections (i.e. sections 3.1.2, 3.2.2 and 3.3.2) were not related to the subjects discussed more frequently in majority of the papers. Therefore, although some of the papers are scanned and mentioned in the 'Methodology' section, they are not cited in terms of their results and findings in order to maintain the organisation of the paper. This is due to the fact that the purpose of this review is to summarise the most important findings of the available publications in relation to the elements of energy trilemma. Additionally, the findings presented in this section have been taken from the clear statements in the papers and are not the personal perception of the authors.

\subsection{Operational analysis}

\subsubsection{Problem formulation and solving}

The problem of operational analysis is to calculate the values of state parameters in IEN, i.e. voltages in electricity, pressures in gas and mass flow rates and temperatures in heat/cooling networks. Once the values of the state parameters are calculated the values of energy flows within IEN are obtained. In this way, a suitable understanding of the performance of IEN in terms of energy trilemma and operability of IEN without violation of operation constraints will be obtained.

In order to perform operational analysis the set of equations of balance of power/gas flows at the buses/nodes of the electricity/gas network are formed. Then, the equations are re-written in terms of state parameters in each network.

For the heating or cooling networks the set of equations of balance of mass flow rate of hot or cold water at the nodes, the correlation between mass flow rate, load, and difference of temperature at the loads and the equations for losses of heat are formed. These equations already contain the state parameters of heating or cooling network.

Regarding the coupling components, since the value of the energy flow on one side is known and input to the problem, the value on the other side can be calculated and considered as the load or generation in the corresponding network.

In order to solve the set of nonlinear equations most of the papers have explicitly mentioned they have used Newton-Raphson method. This is due to the fact that this method finds the problem solution with local quadratic convergence irrespective of the size of the network provided all the state variables are initialised with suitable values and the Jacobian matrix is not singular at the solution point $[10,11]$. Once the set of equations is solved the values of state parameters in all the networks and consequently the power/gas/hot or cold water flows in all the branches of the IEN are determined.

In this way, it is possible to examine if the IEN is physically operable. Also, it is possible to evaluate the performance of the IEN in terms of energy trilemma.

A summary of the popular methods used by the research community for problem formulation and problem solving for operational analysis of IENs is presented in Table 2. It can be seen that the problem can be formulated either as: (i) sequential, in which the model of each network is solved separately and the impact of coupling components is considered as load or source for the other network; or (ii) integrated, in which the models of integrated networks with the coupling components are considered as one model and solved as a whole. 
Table 2 A summary of problem formulation and solving for operational analysis of IENs

\begin{tabular}{|l|l|}
\hline Type of problem formulation & $\begin{array}{l}\text { - Sequential (soft-linked) } \\
\text { - Integrated whole }\end{array}$ \\
\hline Algorithms used for problem solving & $\begin{array}{l}\text { - Newton-Raphson (most popular) } \\
\text { - Hardy-Cross [205] }\end{array}$ \\
\hline
\end{tabular}

\subsubsection{Key findings}

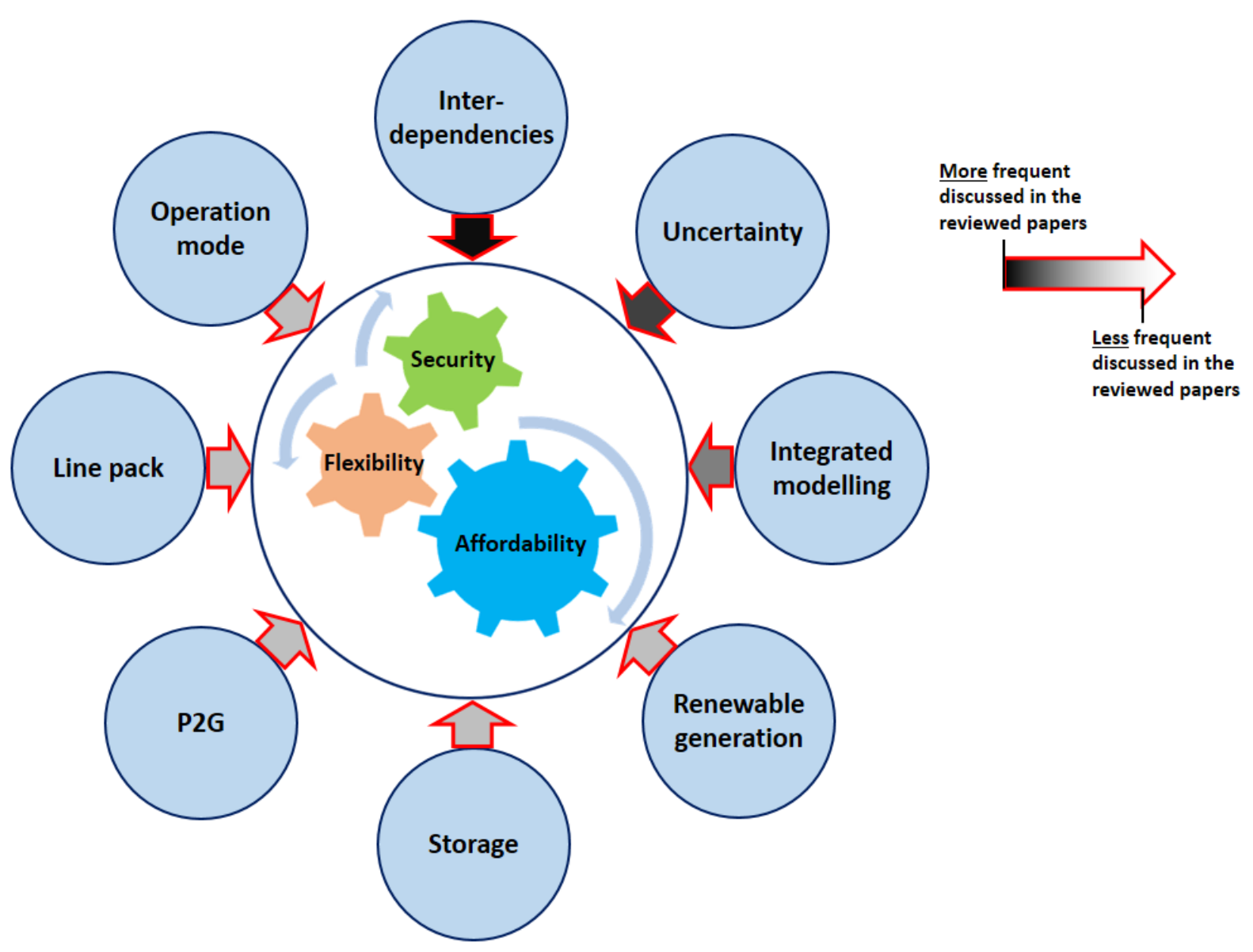

Fig. 5 Topics discussed in the papers on operational analysis of IENs

\section{Flexibility of operation}

Flexibility, as one of the elements of energy trilemma, has been discussed frequently in the papers. There are several options that provide flexibility to the operation of IENs, as follows:

(i) Line pack storage, which is the amount of gas stored in a pipeline, is one of the options that provide flexibility to the gas network as well as to the other coupled networks. The difference between the upper and lower line pack limits of the pipes $(\triangle L P)$ and the amplitude of the line pack swing, impact the line pack flexibility. In a 'Gas based heating' scenario studied in [12] it was found that high heat demand levels lead to a reduction in $\triangle L P$, and hence to a reduction in the flexibility of the gas network. In this scenario, these high heat demands also led to an increase in the magnitude of the line pack swing. 
Therefore, the heat demand levels need to be taken into account in order to evaluate the flexibility of IEN operation. The method developed in [12] to assess the flexibility may be used in scheduling of operation of transmission network. Hence, it is possible to quantify the flexibility in different regions using weather forecasts of day-ahead.

(ii) Power-to-Gas (P2G) facilities, which provide flexibility to the IEN especially at higher levels of wind generation, reduce the power losses and fluctuations of gas pressure [13]. These facilities, which are alternative to gas network reinforcement, effectively benefit the operation of both electricity and gas networks. This is due to the fact that they contribute to the reduction of wind curtailment and to the relief of congestion in the electricity network as well as in the coupled networks to decrease the insecurity risks $[14,15]$.

(iii) Any form of storage devices offers flexibility to the operation of IEN. Different types of energy storage systems that are utilised in gas, electricity and district heating networks are summarised in Table 3. All these different forms provide support, in terms of flexibility of operation, security of supply and affordability, to the network that is utilising the storage device directly, as well as to all the network(s) coupled to this network through coupling components. It is shown in [16] that the heat networks can be considered as thermal storage devices to some extent and provide flexibility to other coupled network(s) through the quasi-dynamic ${ }^{2}$ interactions, which can be used in security enhancement. It is found that in smart energy systems, proper control strategies, which have large influences on the quasidynamic interactions, should be developed to use these interactions for increasing IEN flexibility [16].

Table 3 Different types of energy storage systems utilised in IENs

\begin{tabular}{|l|l|l|}
\hline \multicolumn{1}{|c|}{ Gas network } & \multicolumn{1}{|c|}{ Electricity network } & \multicolumn{1}{c|}{ District heating network } \\
\hline Gas tank & - Batteries & Hot water tank \\
Line pack & - Pumped hydro storage & Geothermal storage \\
& - Compressed air energy storage & Air source heat pump*** \\
& - Liquid air storage & Ground source heat \\
& - Electric vehicles* & pump*** \\
& - Flywheel storage system & \\
& - Hydrogen** & \\
\hline
\end{tabular}

*: through vehicle-to-grid

**: produced from surplus Renewable Energy Sources (RESs), using electrolyser, stored in the gas network and burnt at the time of need

***: acting as the heat supplier to the energy centre (source) of the DHN

(iv) Compressors with dual flow capability can provide flexibility to the IEN in order to accommodate the changes in supply in any of the networks [17].

\section{Security of supply}

Security of supply is another element of energy trilemma and is investigated frequently in the papers. It was shown that IEN support one another in the case of occurrence of faults, however, at a higher cost and emission condition [18]. It was demonstrated that these faults can propagate from

\footnotetext{
2 'Quasi-dynamic' in [16] refers to an integrated model of electricity and heat networks in which the electricity network has been modelled using steady-state formulations, however, time-dependant (dynamic) equations have been used for modelling the heat network.
} 
one network to other coupled networks and cause risks to the IEN operation [19]. Several options were proposed in the literature in order to reduce the risk of occurrence of faults and improve the security of operation of IEN, as follows:

(i) Electrification: electrification of heat and especially using hybrid heating technologies can result in great reductions in GHG emission of electricity and heat sectors and reduce conventional generation peaks [20], which in turn contributes to the secure operation of the IEN. It was suggested that a mixed combination of technologies at district and local levels needs to be considered to meet techno-economic and environmental performance targets as well as to minimise the influence on the constraints of the local network [21].

(ii) Storage: Adding storage in weak parts of the networks is an effective way to decrease operational insecurity and strengthen the system [22].

(iii) Correlations of pipeline parameters: Accurate estimation of distributions and correlations of pipeline parameters need to be considered in order to reduce potential risks to operation of IENs [23].

(iv) Operation mode of coupling components: The operation mode influences the energy flows and IEN operation [24]. For example, at the conditions of high heat demand, a CHP unit in the heat load following mode may generate great amount of electricity and export it to the grid and hence negatively impact the security of supply of the IEN [25]. Considering all the above points can avoid load contingency, which produces frequency deviation and generation re-dispatch that in turn changes the energy flow profiles in the IEN that could cause critical operation condition for the IEN [26].

\section{Aspects impacting the energy trilemma}

\section{Interdependencies}

Interdependencies and coupling components of IEN allow for IEN to have interactions through these components [27]. Disturbance from one network transmits to the other coupled networks through these conversion components [16]. Also, high loads in one network influence the energy flows of the coupled networks through these coupling components [25]. Additionally, conversion technologies at different levels in IEN significantly affect the multi-energy flows in all the coupled networks, and subsequently the IEN emissions and operational costs [21]. The influence of interdependencies on the reliability of the IEN has been studied. Implementation of gas Demand Response (DR) provided additional resilience for the gas network and the IEN, or gas storage increased the IEN reliability [20]. Increasing the number/capacity of coupling components will increase the impacts of failures in the gas network on the electricity network in terms of decrease in the reliability of the electricity network [28]. Moreover, failures in the electricity network can affect the reliability of gas network when the power supply of facilities in gas network is satisfied by electricity. Also, decrease in generation capacity in the electricity network can significantly reduce the reliability of the coupled gas network [28]. Failure in the electricity network was shown to eventually have an effect on the gas system. However, due to the slow dynamics of gas system, the failure in gas system will not be transmitted to the coupled electricity network rapidly [29]. The heat generation technology mix affects both gas and electricity networks as well as their interaction and has impact on the overall IEN operational costs and carbon footprint [30]. CHP units reduce the impact of voltage drop on electricity networks [27] and CHP units with lower heat to electricity ratios have a greater impact on the reduction of IEN losses, due to the fact that the reduction in electric losses that CHP units provide outweighs the increase in gas losses [31]. 


\section{Uncertainty}

Uncertainty within the IEN was another topic investigated in the papers. There are several sources of uncertainty within IENs including renewable energy output, the random outage of generator units, and the random fluctuation of the loads. It was shown that increase in the uncertainty range of these factors leads to great fluctuation of the state variables of the nearby buses/nodes [32]. One of the most important sources of uncertainty is uncertainty of wind, which was studied in several papers. It was found that uncertainty of wind leads to significant risk to the operation security of natural gas systems $[33,34]$ and consequently to the security of real-time operation of IEN [35].

\section{Integrated modelling}

Investigation of modelling aspects of IEN in the papers have shown that all the networks need to be simulated and analysed in an integrated manner. This is due to the fact that a disturbance in one system can influence the other coupled systems. Moreover, the disturbance propagates back to the system where the disturbance initially occurred. Thus, a combined analysis of an IES is required, even if the aim is to investigate the influences on the system itself where the problem occurred [36]. Therefore, there is a need for integrated IEN studies and energy system assessment for the evaluation of system resilience [17] or system flexibility [12]. Additionally, it was shown that in short term operation, steady-state gas flow models could provide less accurate results due to the realtime imbalances of gas flow [35]. Therefore, dynamic or quasi-dynamic simulation needs to be implemented especially in order to quantify the process of interaction between IENs [16].

\subsection{Optimal dispatch}

\subsubsection{Problem formulation and solving}

The problem of optimal dispatch in IENs is normally formulated as a classical optimisation problem with the objective of minimisation of operational costs or equivalently maximisation of social welfare subject to operational constraints as shown in Equations.(1-3).

$$
\operatorname{Min} f(x) \text { or Max } g(x)
$$

s.t.

$$
\begin{aligned}
& H(x)=0 \\
& G(x) \leq 0
\end{aligned}
$$

where:

$f(x)$ : the cost of operation of electricity network (fuel and variable costs of generation, cost of unserved demand, start up and shutdown costs of thermal generating units and cost of electricity load shedding [54-71,114,115,116,120,125,129]), gas network (cost of gas supply from terminals, costs of gas injection into and withdrawal from gas storage facilities, cost of gas provided by line pack and cost of gas load shedding [59-71,124,125]) and heat network (gas/electricity price for heat units, operational cost of heat output and heat input in the storage [72-74]) and carbon emission penalty [75-78].

$g(x)$ : social welfare includes the benefit of energy consumption minus operational costs of the IEN and cost of emissions [79-83] as described for $f(x)$. 
$H(x)$ : energy flow balances in the networks and coupling components

$G(x)$ : operational and capacity constraints (capacities of branches and generation units, the storing and releasing rates and the capacities of storages and line pack, fuel constraints).

$x$ is the vector of variables for decision making which consists of the set-points of: (i) the generation units; or (ii) the dispatch of energy sources; or (iii) the energy conversion of coupling components.

A summary of the popular methods used by the research community for problem formulation and problem solving for optimal dispatch of IENs is presented in Table 4.

Table 4 A summary of problem formulation and solving for optimal dispatch of IENs

\begin{tabular}{|c|c|}
\hline Type of problem formulation & $\begin{array}{l}\text { - Mixed integer nonlinear problem } \\
\text { - Mixed-integer linear problem } \\
\text { - Multi-objective mixed integer nonlinear } \\
\text { problem }\end{array}$ \\
\hline Algorithms/tools used for problem solving & 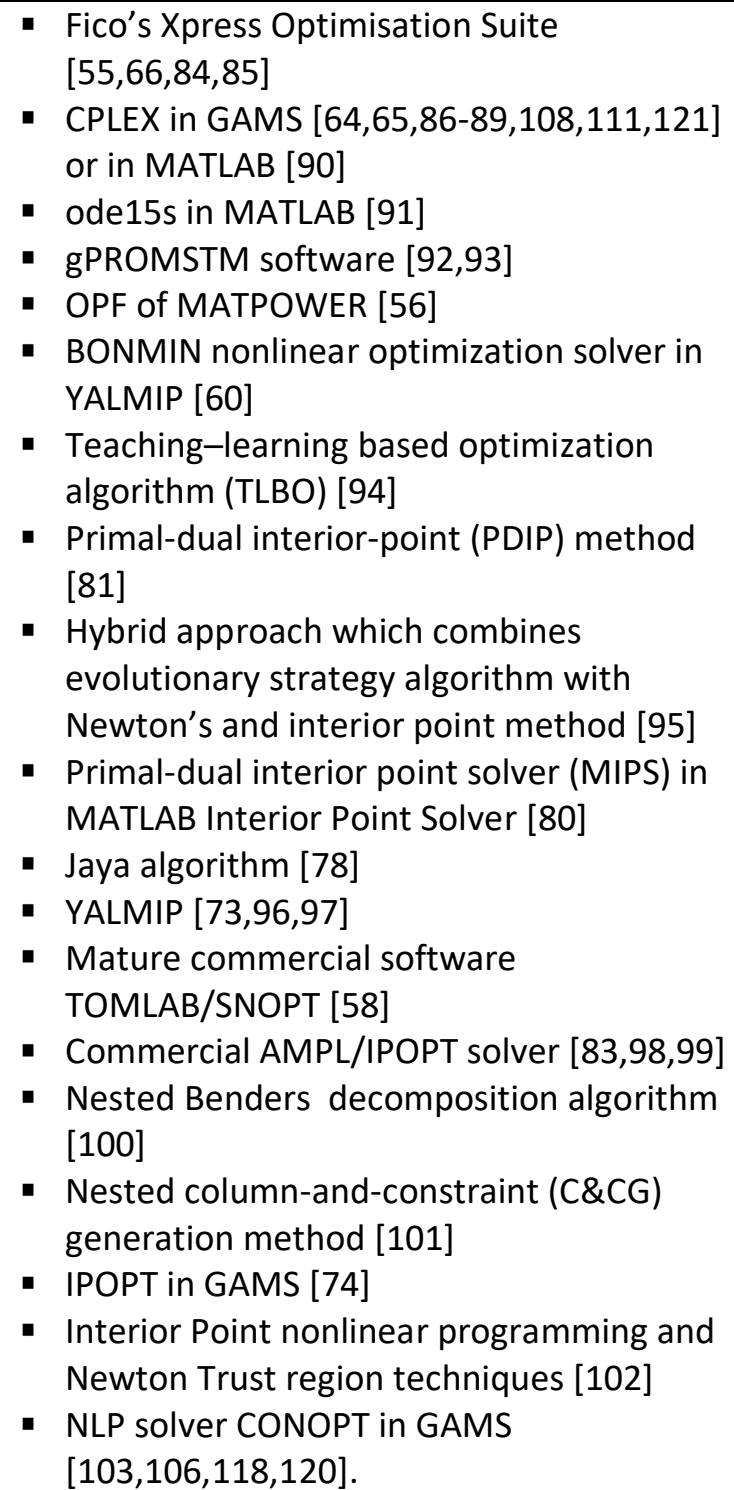 \\
\hline
\end{tabular}




\subsubsection{Key findings}

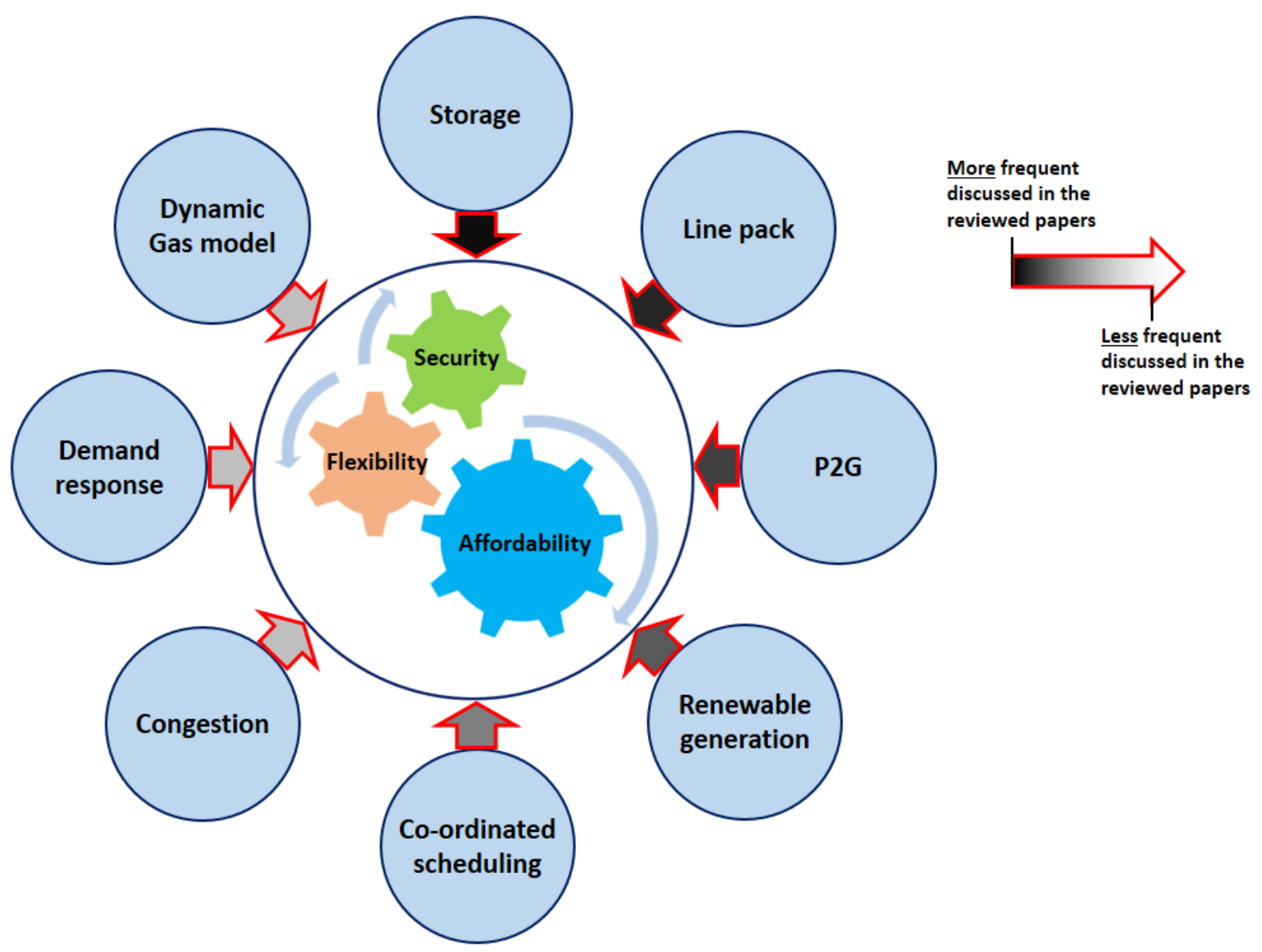

Fig. 6 Topics discussed in the papers on optimal dispatch of IENs

\section{Flexibility of operation}

Flexibility of operation of IEN was the most important and frequent aspect investigated in the references. It was shown that co-optimisation of IENs rather than optimisation of individual networks separate from the other(s) improves the economy and flexibility of the IEN [101,104]. Also, different types of energy storage devices in IENs contribute to the flexible operation of the networks [87]. Inclusion of multi-type storage has also the benefit of reducing the operational uncertainty and the operational costs of IENs introduced by network constraints [105]. Additionally, comparison of impact of P2G and DR in terms of impact on improving the flexibility has shown that P2G has a greater impact compared to DR in terms of improving the flexibility of IENs [106]. Furthermore, it was observed that multi-directional compressors provide additional flexibility to the gas network and hence reduce total operational costs and gas load curtailment as a result of the network flexibility they offer [77]. One of the options for GHG emission reduction that is gaining great attention, is electrification of heat. However, it was shown that increasing flexibility of the electricity network is necessary for electrification of heating for GHG reduction purposes [57]. This flexibility can be provided by integration of heating system and gas system with the electricity system in order to accommodate fluctuations in the electricity system [74]. The dynamic of gas and line pack capabilities in gas networks can provide flexibility and reliability for electricity networks in IEN shortterm operation [59]. 


\section{Security of supply}

Security of supply, and matching the supply and demand, are important aspects discussed in the papers. Importance of the integration of systems in terms of operation, planning, security and reliability was investigated [95]. It was shown that combining gas and electricity networks is important to evaluate energy conversion between networks to minimise risk, ensure IEN security, and match supply with demand whilst minimising cost for transmission [107]. Also, the security constraints of the gas network place limitations on the IEN operation [108]. Additionally, it was found that while dynamic gas system control and increased coordination of IEN each provide benefits, both are essential for security and reduced operational costs in high stress conditions [91]. Furthermore, it was shown that a natural gas shortage will limit electricity generation of gas-fired units and increase the total operational cost of the electricity networks significantly [109]. Moreover, dual-fuel electricity generation units will consume an alternative and even more expensive fuel such as coal in order not to violate the operational security constraints [110].

\section{Aspects impacting the energy trilemma}

\section{Storage}

Storage in IENs was another topic discussed in several papers. In addition to provision of flexibility to the IEN, as discussed previously, storage in IEN decreases load curtailments and improves IEN resilience against contingencies [100]. Gas storage in particular is more effective in managing congested IEN [70] and could greatly reduce shedding and operational costs [85], enhance system resilience [71], and support the operation of IEN [85]. Additionally, it was shown that gas storage in an IEN heavily dependent on gas imports for electricity generation has the ability to hugely reduce the operational costs of the coupled electricity network [55]. Furthermore, it was shown that thermal storage has the benefits of reduction in total operational cost, improving IEN reliability and capability in accommodating more renewables [111]. Integrated analysis rather than analysis of individual system separate from the other(s) is beneficial as it showed gas storage led to decrease in electricity imports in extreme weather conditions [55]. Also, storage could offer greater and safe use of the hydrogen in the gas network [56].

\section{Line pack}

Line pack was another topic discussed in the papers. Apart from being an intrinsic property of gas networks, which contributes to the flexibility of gas networks and consequently to IEN as discussed previously, it was shown that line pack also plays an important role in balancing the production and consumption [90] and contributes to reduction of costs and more economical dispatch [112]. The higher the line pack of the system, the lower operational costs to meet the demand [59].

Additionally, it was demonstrated the lower the line pack, the more the gas supplied from other sources and storages, and hence the more IEN operational costs [64]. In order to simulate the line pack storage and investigate the time evolution of it, dynamic gas flow models instead of steady state models need to be implemented [113]. In this way, it is possible to assess the amount of line pack storage in each single pipe [90]. This also provides the basis for studying security of supply [113], which can be carried out by varying the gas supply profile over the day and hence controlling and simulating the line pack and pressures [114]. Another benefit of application of dynamic gas models is in studying coordinated scheduling since steady-state gas models ignore gas inertia and line pack. This may result in suboptimal or less accurate short-term co-ordinated scheduling of IEN [112]. 
P2G was the most frequent coupling component that was investigated in the papers. It was found that P2G facilities have several benefits including mitigating congestion of gas network as well as the IEN [56,90], avoiding wind curtailment [115], supplying gas demand and improving wind accommodation [74,90], reduction of operational costs of gas networks $[115,116]$ and IEN $[98,108,117,118]$, reduction of IEN emissions $[108,115]$ and enhancing the capability of the IEN in comprehensive utilisation efficiency of energy $[98,108]$. The above benefits allow for additional resilience in ability of the gas network to provide the minimum required offtake pressure [56]. The location of these P2G facilities has impact on their role [90]. P2G units can support more costeffective unit commitment scheduling by avoiding the curtailment of surplus wind generation and converting it into natural gas [96] and hence decrease revenue deficit at higher P2G efficiencies [102]. Furthermore, combined operation of the P2G and gas turbine units can effectively weaken the under/over voltage issues [102].

\section{Renewable generation}

Although different types of renewable generation, including wind and PV, have been investigated, wind generation has been more frequently explored in the papers compared to other types of renewable generation. Wind generation is a highly accessible option for decarbonising electricity and heat demands. It was shown that the electricity generation costs and eventually IEN operational costs reduce as the penetration of wind generation increases $[89,119]$. Also, increased levels of uncertainty of wind generation lead to increased levels of uncertainty of operational costs of IEN [60] and hence to the higher system generation costs [120]. The disadvantages of low wind penetration levels include more supply to gas turbine power plants, more import of expensive electricity, less line pack and flexibility in the gas network, more compressor power consumption and eventually higher IEN operational costs especially in high demand conditions [61]. Several solutions were suggested for reduction of curtailment of wind generation including: (i) P2G units can convert most of the surplus wind into gas and heat [74]. However, due to high operational cost of P2G, to ensure the benefit for both the wind farm and the IEN, cost-benefit trade-off needs to be carried out between wind generation level and IEN operational economy [103]. (ii) Producing hydrogen from electricity reduces wind curtailment in a high wind case and decreases operational costs, GHG emissions and gas flow from gas sources [63]. It was suggested to produce hydrogen at high wind regions by locating electrolysers in those regions [63]. (iii) Increasing the heat pump capacity gradually decreases the rate of wind curtailment [121]. Also, analysis of impact of correlation coefficients between different wind farms on the operational costs showed that if the correlation coefficients between wind farms are larger, the IEN operational costs will be larger too [87].

\section{Co-ordinated scheduling}

Co-ordinated scheduling of integrated networks was investigated in several papers. Comparison of co-ordinated scheduling with co-ordination of networks separate from one another showed that the case of co-ordinated scheduling leads to lower emission and operational costs [122] and stays within the operational constraints especially with higher cost savings at higher load levels [67]. A study with DR found that co-ordinated gas-electricity DR achieves a better IEN economy than single electricity DR or single natural gas DR [60]. Additionally, it was shown that co-ordinated scheduling, which can better handle the inaccuracy of forecasting [73], could help the IENs relieve a contingency in one network, which also impacts operation of the other coupled networks, with lower operational costs compared to non-co-ordinated scheduling [68]. To ensure all the aforementioned benefits of coordinated scheduling, gas and electricity Transmission System Operators (TSOs) need to closely collaborate and co-ordinate [113], which is further discussed in section 4. 


\subsection{Optimal Planning}

\subsubsection{Problem formulation and solving}

The mathematic model for optimal planning of IENs is similar to traditional planning of gas, electricity or heat networks, which can be formulated as a typical optimisation problem. However, compared with the traditional approach, there are more decision variables, more comprehensive objectives, more complex constraints, and higher uncertainty levels in planning models of IEN.

A problem of optimal planning is formulated with the target of minimisation of Net Present Value (NPV) of sum of all the expansion costs consisting of investment costs (or capital costs, CAPEX) and operational costs (OPEX), or maximisation of NPV of social welfare of IEN over the planning horizon subject to operational and investment constraints, as follows:

$$
\operatorname{Min} f(x)=\sum_{t} \tau_{t} \times(I C(x)+O C(x)) \text { or } \operatorname{Max} g(x)=\sum_{t} \tau_{t} \times(B(x)-C(x))
$$

s.t.

$$
\begin{aligned}
& H(x)=0 \\
& G(x) \leq 0
\end{aligned}
$$

where:

$f(x)$ : NPV of all the expansion costs consisting of investment costs $(I C)$ and operational costs $(O C)$

$\tau_{t}=1 /(1+d r)^{t-1}$ : the coefficient of present value of all the expansion costs (CAPEX and OPEX) of the system ( $d r$ : discount rate)

IC $(x)$ : investment costs including cost of new elements within electricity network (electric generators, electricity transmission lines, etc.), within gas network (gas sources, gas pipelines, compressor, gas storage, etc.), and within heat network (new pipes, storage) and new energy conversion units [158-193]

$O C(x)$ : operational costs including cost of operation of the networks (such as maintenance and replacement costs), energy conversion units, unserved energy, reliability cost of networks operation, outage costs of existing and future elements/units, energy losses and emission [158-193]

$g(x):$ NPV of social welfare

$B(x)$ : benefits of the operation of the IEN in meeting the required demand [194-196]

$C(x)$ : total operation and maintenance (investment and operational) costs of operation of the IEN, as above [194-196].

$H(x)$ : the equality constraints representing the energy flow balances in the networks and coupling components

$G(x)$ : the inequality constraints representing the state, construction and investment constraints as well as operational and capacity constraints (capacities of branches and generation units, storing and releasing rates and capacities of storages and line pack, fuel constraints) 
$x$ is the vector of variables for decision making representing the set of operation condition and capacities of the existing and future elements of the networks and generation units, dispatch of energy sources, energy conversion of coupling component, storage capacity, pipeline capacity, etc.

Elements of the energy trilemma are considered either in the objective function or in the constraints to link the models to the analysis and scenarios.

A summary of the popular methods used by the research community for problem formulation and problem solving for optimal planning of IENs is presented in Table 5.

Table 5 A summary of problem formulation and solving for optimal planning of IENs

\begin{tabular}{|c|c|}
\hline Type of Problem formulation & $\begin{array}{l}\text { - Mixed-integer nonlinear problem } \\
\text { - Mixed-integer linear stochastic problem } \\
\text { - Mixed-integer linear problem } \\
\text { - Multi-stage stochastic problem }\end{array}$ \\
\hline Algorithms/tools used for problem solving & $\begin{array}{l}\text { - } \text { CONOPT solver in GAMS [158] } \\
\text { - } \text { Branch-and-Reduce Optimization Navigator } \\
\text { - } \text { Evolver (BARON) in GAMS [159,166,169,172,179] } \\
\text { Beasley genetic algorithm [160] } \\
\text { - } \text { Modified differential evolution (DE) algorithm } \\
\text { with fitness sharing [163,194] } \\
\text { - } \text { CPLEX solver in GAMS } \\
\text { - }[164,170,173,176,181,182,184,186,187,189,192] \\
\text { framended Mathematical Programming (EMP) } \\
\text { - } \text { MATLAB/YALMIP/GUROBI solver [168] } \\
\text { - DIscrete and Continuous OPTimizer (DICOPT) in } \\
\text { - GAMS [172] } \\
\text { - Modified binary particle swarm optimization } \\
\text { - Non-dominated Sorting Genetic Algorithm-II } \\
\text { (NSGAll) implemented in MATLAB [185] } \\
\text { - Gurobi [190] } \\
\text { - DECIS solver in GAMS }\end{array}$ \\
\hline
\end{tabular}

\subsubsection{Key findings}




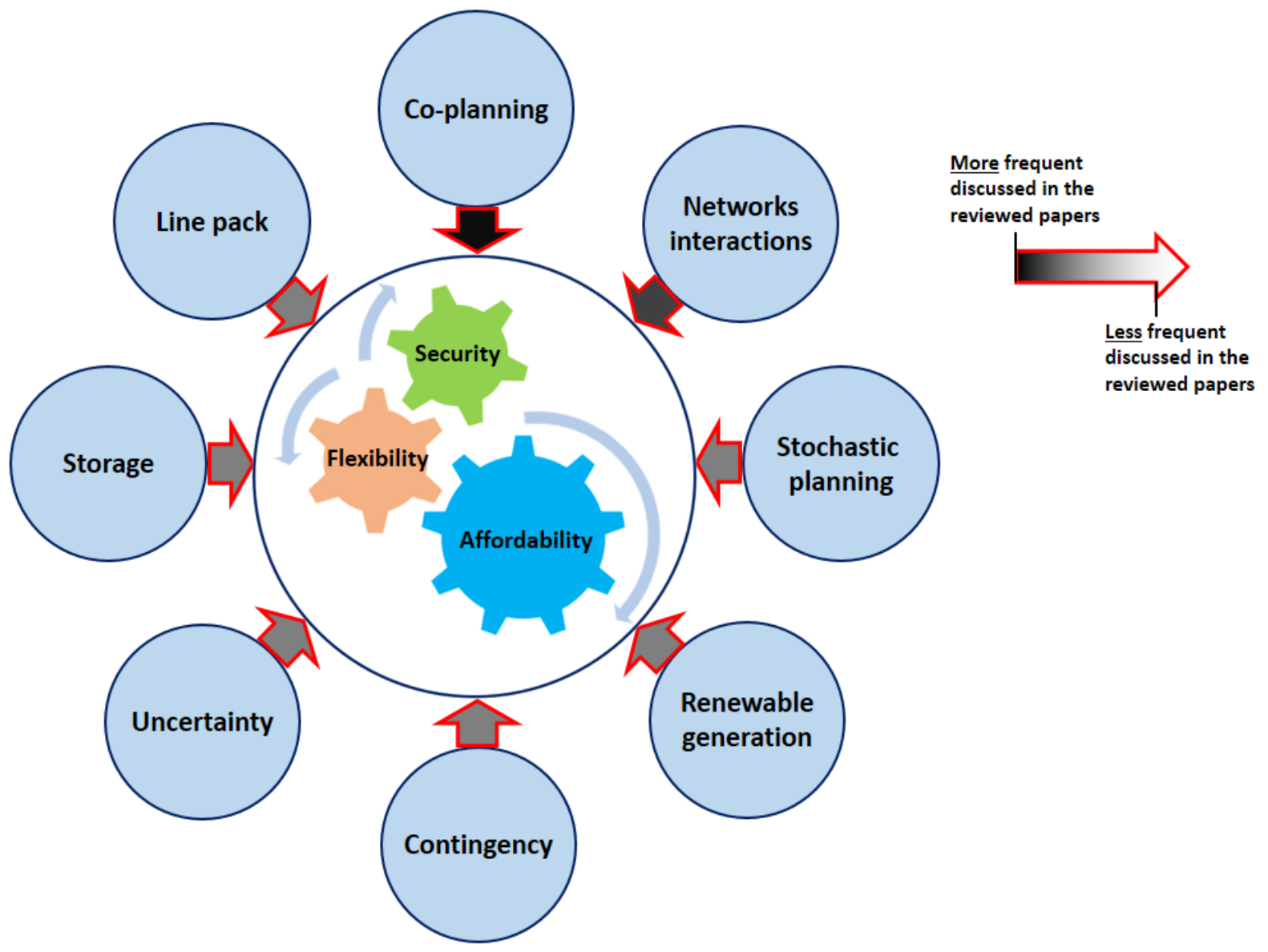

Fig. 7 Topics discussed in the papers on optimal planning of IENs

\section{Flexibility of operation}

It was shown that all the energy storage systems contribute in the long term to avoid energy deficiency and hence to increase economic savings [177]. Among different storage types, additional gas storage facilities could enhance gas availability and line pack during periods of high gas load levels [165]. Also, gas storage devices are effective in mitigating the impact of uncertainty of the demand on the long-term planning of IENs and in enhancing the security of energy supply [169]. It was found that in the co-planning, line pack varies and decreases more in high load conditions [167]. Also, P2G units can support IENs to benefit from more RESs penetration, delay electricity transmission lines construction [190] and improve costs, emissions and heat profit of IENs [198]. Additionally, compressors can postpone building gas pipelines and hence decrease IEN costs [190].

\section{Aspects impacting the energy trilemma}

It was found that heat demand needs to be considered in operational planning of the flexibility of IENs [12]. Also, in order to consider the uncertain future demand and generation, stochastic solutions need to be investigated, which present the lowest expected cost for this purpose [176], and hence does not result in any load curtailment [164]. It was also found that demand uncertainty impacts the operational cost and not the investment cost [160]. Moreover, the more the reliability of satisfying the stochastic demand, the more the investment cost. Especially in IENs where the electricity network is highly dependent on the gas system, increasing the reliability of the gas system significantly increases the reliability of the whole IEN [169]. Also, increase in the level of stress within the IEN increases both the cost of operation and investment [184]. It was found that N-1 contingency of natural gas transmission network has large impact on planning of IENs, especially in 
the regions with limited natural gas resources [170]. Also, it was shown that installation of new pipelines or incorporation of fuel switching capabilities are effective solutions to relieve fuel supply constraints and reduce the total operational costs [191].

\section{Co-planning}

Co-planning of IENs has been compared against sequential or separate planning in several papers and several benefits in terms of above aspects around the energy trilemma have been investigated. It was found that co-planning of IENs finds a solution with the following characteristics compared to sequential or separate planning, due to the fact that it considers strategically all the networks and their interactions:

- lower total costs (investment and operational) [158,167,168,170,171,174,179$183,186,188,190,193,197]$, or equivalently higher social welfare [194-196]. Especially the higher load growth rates, the higher benefit to cost ratios [167]. This is due to the fact that IEN has an infrastructure capable of levelling the loads in different vectors and hence it can relieve transmission stress and postpone construction investment and operational costs $[172,174]$.

- lower carbon emissions $[167,189]$

- less load curtailment [171,181]

- higher robustness and reliability levels while accommodating different uncertainties in the IEN $[167,172,179,185,189,195,196]$. Also, if operational constraints are neglected, e.g. power imbalance is allowed, then the total cost decreases since certain investments can be avoided [190].

- more flexible [196] and enhanced resilience levels [186]

- less transmission and energy losses $[181,196]$ and hence higher efficiency of the energy grids and better infrastructure utilisation efficiency $[162,181,189,195,196]$ due to maximised transfer capabilities within all the vectors [196].

\section{Networks interactions}

Natural Gas-fired Power Plants (NGPP) have been investigated more compared to other possible coupling components for the operational planning of IENs in the literature. It was found that installation of NGPPs reduces investment [158] as well as the total operational costs, as this guarantees security of the electricity network [170] and NGPPs and system transmission capacity are efficiently utilised [167] (despite the growth in operational costs of the gas network due to building more infrastructure [192]). Also, it is necessary to integrate more NGPPs to increase the reliability over the planning horizon $[159,179]$. Also, the sensitivity of the integrated networks design to the confidence level is dependent on the quantised size of the candidate NGPPs and the level of the electricity demand [179]. It was found that the constraints of transport of natural gas has influence on the planning of the electricity system, especially in regions where the candidate NGPPs depend massively on a constant supply of natural gas [191].

\section{Research needs, gaps and future research direction recommendation}

The systematic review has identified the following gaps for future research in operation, dispatch and planning of multi-vector energy networks.

\subsection{Smart energy management framework}


There is a need for development of advanced control and management frameworks in order to perform online optimal dispatch of IENs based on historical and online data that are further processed by Artificial Intelligence (AI) and Machine Learning (ML) techniques. This framework needs to be deployed through Internet of Things (IOT) framework since there is a growing attraction in online acquisition and storage of data in loT frameworks. Additionally, energy networks are becoming more integrated through several coupling components. As a result of vector integration using ICT systems and data collection through loT frameworks, cyber attacks are considered as a potential threat to the operation of multi-vector energy networks. Therefore, loT-driven control and management frameworks for IENs considering Al, ML and cyber security assessment needs to be investigated and deployed on energy networks, with a single multi-vector owner for test and validation purposes (Fig 8). In this way, the studies that have been carried out on security and resilience of future electricity grids [201] can be further extended to future IENs.

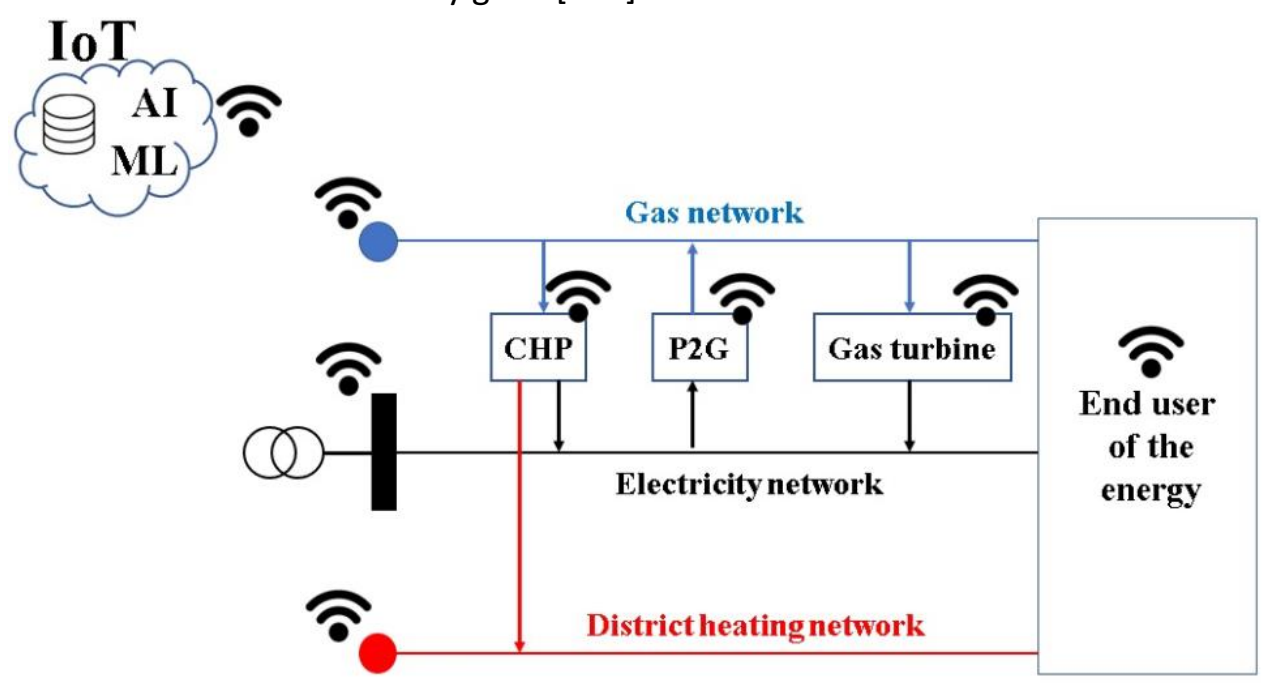

Fig 8 The schematic of smart management of IENs through loT frameworks

\subsection{Organisational and regulatory barriers for the future integrated control rooms}

The benefits of integrated optimal planning and dispatch of energy networks have been investigated in several publications and have been summarised in this paper. However, in reality these networks, which are coupled at several locations, are planned and operated separate from each other in transmission level all the way to medium level distribution level since they are owned, operated and governed by different companies/governments/regulators. As a consequence, if a fault/contingency occurs in one of the networks, the operator of that network attempts to find the solution within that network, whereas, the other coupled network(s) might be able to provide some support/service to relieve this affected network (Fig 9). However, integrated control and management of coupled networks in one central location has not yet been investigated, due to the following facts: (i) each energy network has its own control room separate from the control room of the other coupled energy network(s); (ii) organisational policies, procedures and regulation of each network operator is different from the other one. In order to benefit from the advantages of integrated planning and control of coupled energy networks the operators of the networks need to be in one central location and communicate with each other in order to find a practical solution for planning of the networks or for fault/contingency relief in case of occurrence of any fault/contingency in either network. 


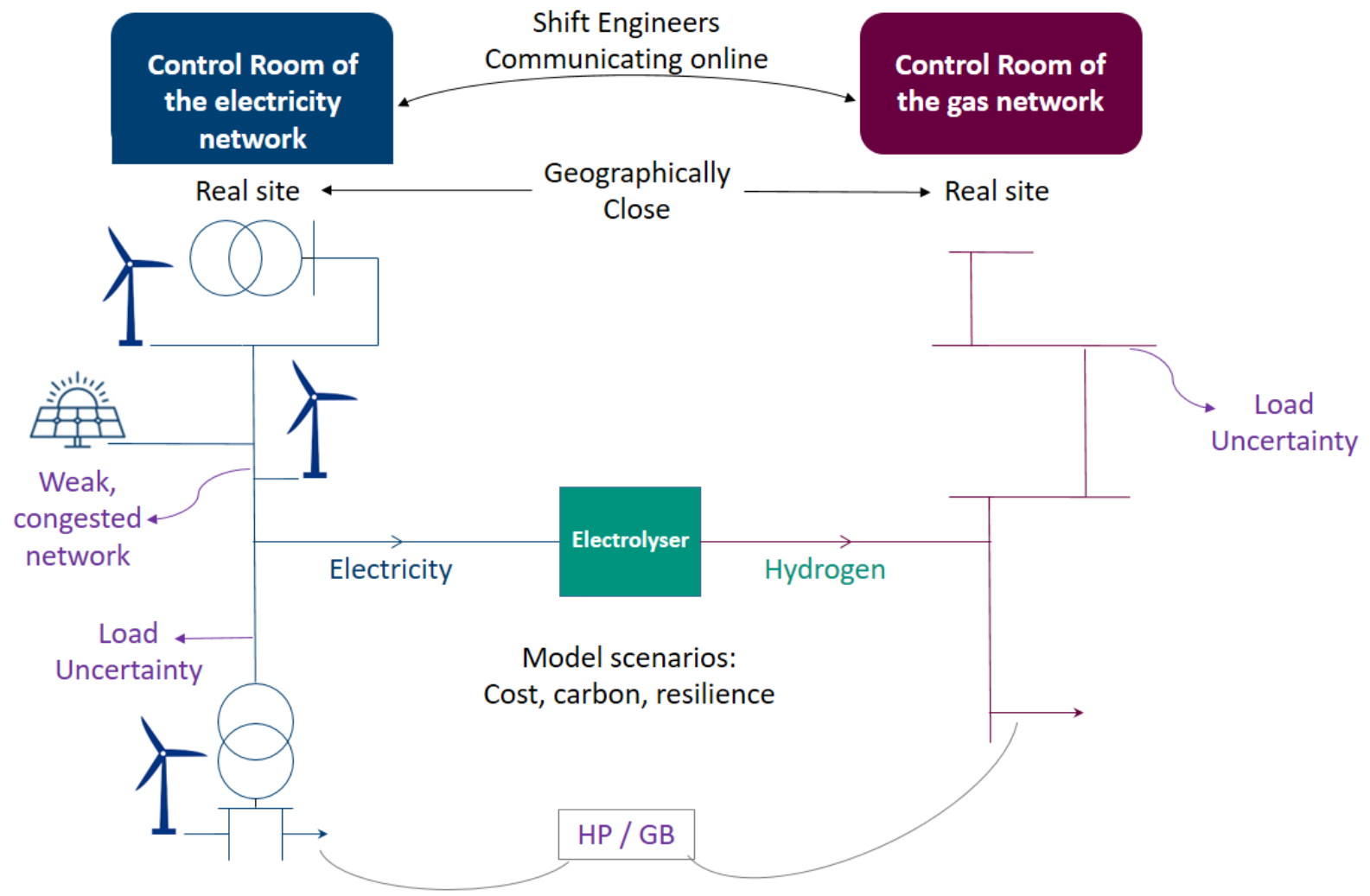

Fig 9 The schematic of control rooms of the future for integrated gas and electricity networks

Hence, some relevant questions need to be considered in the phase of designing the control rooms of future such as:

- How well do the tasks and roles in different control rooms correspond?

- Are there different levels of urgency or extent of active intervention needed?

- At what scale of production does gas-for-storage become significant on either side?

- What regulatory, market or institutional factors might affect co-operation?

- How could control room practices be adapted to enable new possibilities for energy storage?

\subsection{Impact of uncertainties on the trilemma evaluation of performance of IEN}

Impact of uncertainty of renewable generation and loads on the energy trilemma have been investigated in several publications. However, uncertainties of the following have not yet been evaluated: (i) the physical characteristics of the energy networks and coupling components normally deteriorate over time. No models have yet been developed to correlate the impact of aging of the physical assets on deterioration of physical characteristics of the networks and hence on the operation and energy trilemma; (ii) dynamic behaviour of the networks have been investigated in several papers. However, ideal networks with perfect assumptions have always been considered for this purpose. These model simplifications and perfect assumptions help a model to run and produce results faster. However, this happens at the expense of some uncertainty in the results based on which the operator of the network wants to make the right decision at the right time. To conclude, there is a need to evaluate the extent of impact of these modelling uncertainties on the energy trilemma performance evaluation of IEN to obtain a tolerance range when reporting the performance of IEN. This especially applies to high level integrated networks such as transmission or high level distribution networks, where great amounts of energy carriers are transmitted over long 
distances and even minor miscalculations can have great consequences on the energy trilemma performance evaluation of IEN (Fig 10).

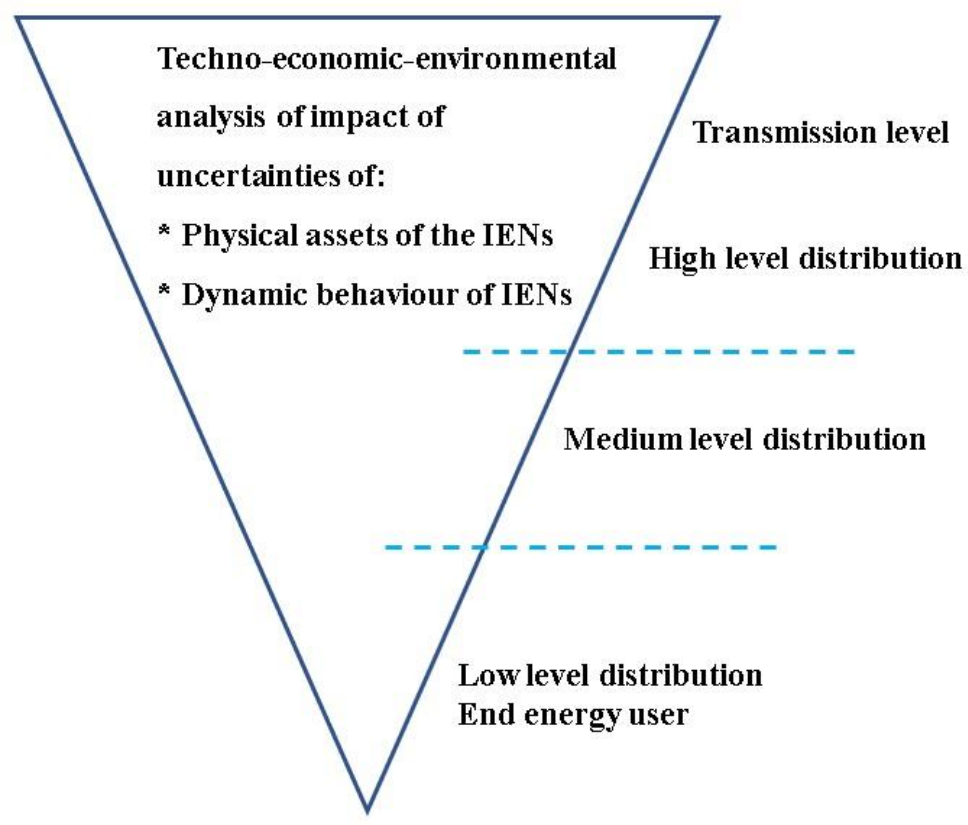

Fig 10 Greater impact of uncertainties on transmission level compared to low level distribution

\subsection{Economics of energy system integration}

Several technical benefits around the elements of energy trilemma have been investigated for integrated operational analysis of coupled networks by different researchers, which have been summarised in this paper. However, networks operate under the constraints of market, regulatory, and policy frameworks through price signals, taxes, and other incentives [202]. The more integration of the networks the more complexity is introduced in the linkages between the operators of the coupled networks. There is, therefore, a need to investigate which level (i.e., transmission or distribution) and to what extent is best to have more integration in the networks in order to better resolve the energy trilemma challenges and to explore whether the economic network integration benefits can be improved through amendments to market, regulatory and policy constraints. If one of the levels was found as the best level to have more integration, then what would be the added value of integration of operation in the other level in terms of the marginal benefits for the whole energy system.

\subsection{Deployment of smart multi-energy regions}

With increasing linkages between gas, electricity and district heating networks, deployment of smart multi-energy in regions rather than districts is gaining attention in the energy research community $[105,56]$. The very first challenging step to deploy these regions is development of models for optimal planning and dispatch and operational analysis of these regions. However, there are several challenges associated with this step, which need further investigation and are summarised as follows:

(i) Developing dynamics of the gas and district heating networks [4];

(ii) Convergence and optimality of the solutions of the models without compensation for accuracy [4];

(iii) TEE impact of renewable energy generation at the building level, e.g. PV and solar thermal, on the IENs [27]; 
(iv) Development of control strategies that can be used for close-to real-time simulation [27];

(v) TEE impact analysis of the flexibility offered by P2G on operation of the IENs [21,57];

(vi) Forecasting the demand (heat and electricity) and optimum utilisation of the flexibility of the multi-energy system [12];

(vii) Quantification and evaluation of the TEE impact of natural disasters on the resilience of the smart multi-energy IENs [17];

(viii) TEE evaluation of benefits of seasonal storage and the impact on the IENs while transporting the gas produced by P2G to the seasonal storage facilities [56].

\section{Conclusions}

This paper summarises the most important findings of recent literature on analysis of multi-vector energy networks, rather than energy hubs, in relation to the elements of energy trilemma: flexibility of operation, security of supply and affordability. The papers have been classified into three groups: (i) Operational analysis; (ii) Optimal dispatch; and (iii) Optimal planning. The focus of the paper has been on energy networks since the main parts of the whole energy system that connect the natural resources and import to the final energy user are energy networks including gas, electricity and district heating/cooling networks along with the couplings and interactions that occur between them both at transmission and distribution levels. Also, the focus of this paper has been on key findings rather than the energy models since the models developed for simulation and analysis of Integrated Energy Networks (IEN) have been reviewed in several other literature. The key findings of the most recent papers have been explained in relation to the elements of energy trilemma. The main driver for this paper was to identify the gaps in the state of the art in the area of multi-vector energy networks research and to articulate this through the lens of the energy trilemma.

The paper makes recommendations for future research priorities including: development and demonstration of cyber resilient smart energy management frameworks, ways to overcome organisational and regulatory barriers for future increased energy network integration, uncertainty analysis of the future performance of IEN, potential economic value of energy systems integration and deployment of smart multi-energy regions.

The paper provides useful insights for the energy research community by presenting several novel ideas for future research and facilitating the path to a decarbonised economy, due to the comprehensive systematic review that has been carried out.

\section{Acknowledgements}

The authors would like to acknowledge Professor Tooraj Jamasb and Dr Manuel Llorca from Department of Economics, Copenhagen School of Energy Infrastructure (CSEI) for their support in preparation of the 'Economics of energy system integration' sub-section in the 'Research needs, gaps and future research direction recommendation' section of the paper.

This work has been funded by EPSRC National Centre for Energy Systems Integration (CESI) (grant number: EP/P01173/1).

Many thanks to the associate editor and the anonymous expert reviewers to provide useful feedback and help the quality of the paper reaches professional standards.

\section{References}


[1] Committee on Climate Change. Net Zero - The UK's contribution to stopping global warming, https://www.theccc.org.uk/publication/net-zero-the-uks-contribution-to-stopping-global-warming/; 2019 [accessed 28 October 2019].

[2] Eusgel I, Nan C, Dietz S. System-of-systems approach for interdependent critical infrastructures. Reliability Engineering \& System Safety 2011;96(6);679-86.

[3] Abeysekera M, Wu J, Jenkins N. Integrated energy systems: An overview of benefits, analysis methods, research gaps and opportunities. HubNet Position Paper Series 2016.

[4] Loukarakis E, Mancarella P. A sequential programming method for multi-energy districts optimal power flow. In: 2017 IEEE Manchester PowerTech; 2017 June 18-22; Manchester, United Kingdom.

[5] Wu J, Yan J, Desideri U, Deconinck G, Madsen H, Huitema G, et al. Synergies between energy supply networks. Applied Energy 2017;192;263-7.

[6] Mancarella P. MES (multi-energy systems): An overview of concepts and evaluation models. Energy 2014;65;1-17.

[7] Wu J, Yan J, Jia H, Hatziargyriou N, Djilali N, Sun H. Integrated energy systems. Applied Energy 2016; 167;155-7.

[8] Lopiona P, Markewitza P, Robiniusa M, Stoltena D. A review of current challenges and trends in energy systems modelling. Renewable and Sustainable Energy Reviews 2018;96;156-66.

[9] Subramanian ASR, Gundersen T, Adams TA. Modeling and simulation of energy systems: A review. Processes 2018;6(12);238.

[10] Martínez-Mares A, Fuerte-Esquivel CR. A Unified Gas and Power Flow Analysis in Natural Gas and Electricity Coupled Networks. IEEE Transactions on Power Systems 2012;27(4);2156-66.

[11] Ortega JM, Rheinboldt WC. Iterative Solutions of Nonlinear Equations in Several Variables. New ed. Philadelphia: Society for Industrial and Applied Mathematics; 2000.

[12] Clegg S, Mancarella P. Assessment of the impact of heating on integrated gas and electrical network flexibility. In: 2016 Power Systems Computation Conference (PSCC); 2016 June 20-24; Genoa, Italy.

[13] Zeng Q, Fang J, Li J, Chen Z. Steady-state analysis of the integrated natural gas and electric power system with bi-directional energy conversion. Applied Energy 2016;184;1483-92.

[14] Chen S, Wei Z, Sun G, Cheung KW, Sun Y. Multi-linear probabilistic energy flow analysis of integrated electrical and natural-gas systems. IEEE Transactions on Power Systems 2017;32(3);1970-9.

[15] Ziarmal H, Farag HE, El-Taweel NA, Abdelaziz M. A co-simulation platform for power and gas distribution networks. In: 2017 IEEE 6th International Conference on Renewable Energy Research and Applications (ICRERA); 2017 Nov 5-8; San Diego, CA, USA.

[16] Pan Z, Wu J, Sun H, Guo Q, Abeysekera M. Quasi-dynamic interactions and security control of integrated electricity and heating systems in normal operations. CSEE Journal of Power and Energy Systems 2019;5(1);120-9.

[17] Clegg S, Mancarella P. Integrated electricity-heat-gas network modelling for the evaluation of system resilience to extreme weather. In: 2017 IEEE Manchester PowerTech; 2017 June 18-22; Manchester, United Kingdom. 
[18] Hosseini SHR, Allahham A, Taylor P. Techno-economic-environmental analysis of integrated operation of gas and electricity networks. In: 2018 IEEE International Symposium on Circuits and Systems (ISCAS); 2018 May 27-30; Florence, Italy.

[19] Wang H, Wang X, Ren Z, Wang X, He Z. Risk assessment of integrated energy system based on electrical-thermal energy flow. In: 2018 2nd IEEE Conference on Energy Internet and Energy System Integration (EI2); 2018 Oct 20-22; Beijing, China.

[20] Clegg S, Mancarella P. Integrated electricity-heat-gas modelling and assessment, with applications to the Great Britain system. Part II Transmission network analysis and low carbon technology and resilience case studies. Energy 2019;184;191-203.

[21] Liu X, Mancarella P. Modelling, assessment and Sankey diagrams of integrated electricity-heat-gas networks in multi-vector district energy systems. Applied Energy 2016;167;336-52.

[22] Zhao B, Luo B, Zhou J, Meng X, Li Z. Static sensitivity analysis method of integrated energy system based on power flow model. In: 2018 2nd IEEE Conference on Energy Internet and Energy System Integration (EI2); 2018 Oct 20-22; Beijing, China.

[23] Jiandong D, Zhuanting J. Probabilistic power and gas flow analysis for electricity-gas coupled networks considering uncertainties in pipeline parameters. In: 2017 IEEE Conference on Energy Internet and Energy System Integration (EI2); 2017 Nov 26-28; Beijing, China.

[24] Hu X, Yang L, Zhao X, Yan W. Probabilistic energy flow analysis for urban energy systems considering correlated uncertainties. Energy Procedia 2019;158;6472-7.

[25] Abeysekera M. Combined analysis of coupled energy networks [dissertation]. Cardiff University; 2016.

[26] Martínez-Mares A, Fuerte-Esquivel CR. Integrated energy flow analysis in natural gas and electricity coupled systems. In: 2011 North American Power Symposium; 2011 Aug 4-6; Boston, MA, USA.

[27] Liu X, Mancarella P, Wu J. A tool for integrated analysis of multi-vector district energy networks. In: 2015 IEEE Eindhoven PowerTech; 2015 June 29 - July 2; Eindhoven, Netherlands.

[28] Bao M, Ding Y, Singh C, Shao C. A multi-state model for reliability assessment of integrated gas and power systems utilizing universal generating function techniques. IEEE Transactions on Smart Grid 2019;10(6);627183.

[29] Erdener BC, Pambour KA, Lavin RB, Dengiz B. An integrated simulation model for analysing electricity and gas systems. Electrical Power and Energy Systems 2014;61;410-20.

[30] Clegg S, Mancarella P. Integrated electrical and gas network modelling for assessment of different power-and-heat options. In: 2014 Power Systems Computation Conference; 2014 Aug 18-22; Wroclaw, Poland.

[31] Acha S, Hernandez-Aramburo C. Integrated modelling of gas and electricity distribution networks with a high penetration of embedded generation. In: CIRED Seminar 2008 SmartGrids for Distribution; 2008 June 23-24; Frankfurt, Germany.

[32] Hu Y, Lian H, Bie Z, Zhou B. Unified probabilistic gas and power flow. Journal of Modern Power Systems and Clean Energy 2017;5(3);400-11. 
[33] Qiao Z, Guo Q, Sun H, Pan Z, Liu Y, Xiong W. An interval gas flow analysis in natural gas and electricity coupled networks considering the uncertainty of wind power. Applied Energy 2016;201;343-53.

[34] Qiao Z, Huang S, Li R, Guo Q, Sun H, Pan Z. Unified power flow analysis in natural gas and electricity coupled networks considering the uncertainty of wind power. Energy Procedia 2016;103;322-7.

[35] Chen S, Wei Z, Sun G, Wang D, Zang H. Steady state and transient simulation for electricity-gas integrated energy systems by using convex optimisation. IET Generation, Transmission \& Distribution 2018;12(9);2199-206.

[36] Pan Z, Guo Q, Sun H. Interactions of district electricity and heating systems considering time-scale characteristics based on quasi-steady multi-energy flow. Applied Energy 2016;167;230-43.

[37] Drauz SR, Spalthoff C, Würtenberg M, Kneikse TM, Braun M. A modular approach for co-simulations of integrated multi-energy systems: Coupling multi-energy grids in existing environments of grid planning \& operation tools. In: 2018 Workshop on Modeling and Simulation of Cyber-Physical Energy Systems (MSCPES); 2018 Apr 10; Porto, Portugal.

[38] Martinez-Mares A, Fuerte-Esquivel CR. A unified gas and power flow analysis in natural gas and electricity coupled networks. IEEE Transactions on Power Systems 2012;27(4);2156-66.

[39] Shabanpour-Haghighi A, Seifi AR. An integrated steady-state operation assessment of electrical, natural gas, and district heating networks. IEEE Transactions on Power Systems 2016;31(5);3636-47.

[40] Katsavounis K, Hou P, Hu W, Chen Z. Comparative study of integrated energy system modelling. In: 2017 IEEE PES Innovative Smart Grid Technologies Conference Europe (ISGT-Europe); 2017 Sept 2629; Torino, Italy.

[41] Jiang Z, Zhang L, Ren Z, Chen Y, Huang S. Coupled analysis of energy flow in a multiple energy system. In: 2017 IEEE Conference on Energy Internet and Energy System Integration (EI2); 2017 Nov 26-28; Beijing, China.

[42] Shi J, Wang L, Wang Y, Zhang J. Generalized energy flow analysis considering electricity gas and heat subsystems in local-area energy systems integration. Energies 2017;10(4);514.

[43] Abeysekera $\mathrm{M}$, Wu J. Method for simultaneous power flow analysis in coupled multi-vector energy networks. Energy Procedia 2015;75;1165-71.

[44] Chen H, Qiu M, Ge H, Li M. The application of energy network theory in the analysis of district electricity and heating system. In: 2017 IEEE International Conference on Energy Internet (ICEI); 2017 Apr 17-21; Beijing, China.

[45] Liu X. Combined analysis of electricity and heat networks [dissertation]. Cardiff University; 2013.

[46] Chen H, Qiu M, Ngan H. Energy network theory for modeling and analysis of integrated energy systems. In: 2018 International Conference on Power System Technology (POWERCON); 2018 Nov 68; Guangzhou, China.

[47] Ruf J, Zimmerlin M, Sauter PS, Köppel W, Suriyah MR, Kluwe M, et al. Simulation framework for multi-carrier energy systems with power-to-gas and combined heat and power. In: 2018 53rd International Universities Power Engineering Conference (UPEC); 2018 Sept 4-7; Glasgow, UK.

[48] Hosseini SHR. State estimation of integrated power and gas distribution networks [dissertation]. Cardiff University; 2017. 
[49] Pambour KA, Erdener BC, Bolado-Lavin R, Dijkema GPJ. An integrated simulation tool for analyzing the operation and interdependency of natural gas and electric power systems. In: PSIG Annual Meeting; 2016 May 10-13; Vancouver, Canada. Houston, TX: Pipeline Simulation Interest Group.

[50] Qin X, Shen X, Sun H, Guo Q. A quasi-dynamic model and corresponding calculation method for integrated energy system with electricity and heat. Energy Procedia 2019;158;6413-8.

[51] Fu X, Li P, Wang C, Mahseredjian J. Extended MANA formulation for time-domain simulations of combined power and gas networks. Energy Procedia 2019;158;6576-81.

[52] Tian X, Zhouhong L, Zhaoguang P, Hongbin S. Modeling and simulation for multi energy flow coupled network computing. In: 2018 International Conference on Power System Technology (POWERCON); 2018 Nov 6-8; Guangzhou, China.

[53] Zhang H, Ouyang M, Wu S, Hong L. Simplified operation models of integrated power and gas systems for vulnerability analysis. Physica A: Statistical Mechanics and its Applications 2019;531;121428.

[54] Urbina M, Li Z. A combined model for analyzing the interdependency of electrical and gas systems. In: 2007 39th North American Power Symposium; 2007 Sept 30 - Oct 2; Las Cruces, NM, USA.

[55] Devlin J, Li K, Higgins P, Foley A. A multi vector energy analysis for interconnected power and gas systems. Applied Energy 2017;192;315-28.

[56] Clegg S, Mancarella P. Integrated modeling and assessment of the operational impact of power-togas (P2G) on electrical and gas transmission networks. IEEE Transactions on Sustainable Energy 2015;6(4);1234-44.

[57] Clegg S, Mancarella P. Integrated electrical and gas network flexibility assessment in low-carbon multi-energy systems. IEEE Transactions on Sustainable Energy 2016;7(2);718-31.

[58] Manshadi SD, Khodayar ME. Coordinated operation of electricity and natural gas systems: A convex relaxation approach. IEEE Transactions on Smart Grid 2019;10(3);3342-54.

[59] Correa-Posada CM, Sánchez-Martín P. Integrated power and natural gas model for energy adequacy in short-term operation. IEEE Transactions on Power Systems 2015;30(6);3347-55.

[60] Bai L, Li F, Cui H, Jiang T, Sun H, Zhu J. Interval optimization based operating strategy for gaselectricity integrated energy systems considering demand response and wind uncertain. Applied Energy 2016;167(1);270-9.

[61] Qadrdan M, Chaudry M, Ekanayake J, Wu J, Jenkins N. Impact of wind variability on GB gas and electricity supply. In: 2010 IEEE International Conference on Sustainable Energy Technologies (ICSET); 2010 Dec 6-9; Kandy, Sri Lanka.

[62] Qadrdan M, Wu J, Jenkins N, Ekanayake J. Operating strategies for a GB integrated gas and electricity network considering the uncertainty in wind power forecasts. IEEE Transactions on Sustainable Energy 2014;5(1);128-38.

[63] Qadrdan M, Abeysekera M, Chaudry M, Wu J, Jenkins N. Role of power-to-gas in an integrated gas and electricity system in Great Britain. International Journal of Hydrogen Energy 2015;40(17);576375. 
[64] Correa-Posada CM, Sánchez-Martín P, Lumbreras S. Security-constrained model for integrated power and natural-gas system. Journal of Modern Power Systems and Clean Energy 2017;5(3);32636.

[65] Correa-Posada CM, Sánchez-Martın P. Security-constrained optimal power and natural-gas flow. IEEE Transactions on Power Systems 2014;29(4);1780-7.

[66] Qadrdan M, Chaudry M, Wu J. Vulnerability analysis of the integrated energy infrastructure. In: 2009 44th International Universities Power Engineering Conference (UPEC); 2009 Sept 1-4; Glasgow, UK.

[67] Jiang Y, Xu J, Sun Y, Wei C, Wang J, Liao S, et al. Coordinated operation of gas-electricity integrated distribution system with multi-CCHP and distributed renewable energy sources. Applied Energy 2018;211;237-48.

[68] Sardou IG, Khodayar ME, Ameli MT. Coordinated operation of natural gas and electricity networks with microgrid aggregators. IEEE Transactions on Smart Grid 2018;9(1);199-210.

[69] Shahidehpour M, Wen F, Li Y, Li Z. Minimax-regret robust co-optimization for enhancing the resilience of integrated power distribution and natural gas system. IEEE Transactions on Sustainable Energy 2018;Early Access Article.

[70] He Y, Shahidehpour M, Li Z, Guo C, Zhu B. Robust constrained operation of integrated electricitynatural gas system considering distributed natural gas storage. IEEE Transactions on Sustainable Energy 2018;9(3);1061-71.

[71] He C, Dai C, Wu L, Liu T. Robust network hardening strategy for enhancing resilience of integrated electricity and natural gas distribution systems against natural disasters. IEEE Transactions on Power Systems 2018;33(5);5787-98.

[72] Chen Y, Wei W, Liu F, Mei S, Huang S. A game model for multi-energy transaction in a gas-heatpower network-coupled system. In: 2017 36th Chinese Control Conference (CCC); 2017 July 26-28; Dalian, China.

[73] Li B, Roche R, Paire D, Miraoui A. Coordinated scheduling of a gas electricity heat supply network considering temporal-spatial electric vehicle demands. Electric Power Systems Research 2018;163(Pt A);382-95.

[74] Zeng Q, Fang J, Zhang B, Chen Z. The coordinated operation of electricity, gas and district heating systems. Energy Procedia 2018;145;307-12.

[75] Qu K, Yu T, Huang L, Yang B, Zhang X. Decentralized optimal multi-energy flow of large-scale integrated energy systems in a carbon trading market. Energy 2018;149;779-91.

[76] Wu, L.L., Wu, Q.H., Jing, Z.X., Wei, F., Deng, S. and Zhou, X.X., 2016, November. Optimal power and gas dispatch of the integrated electricity and natural gas networks. In 2016 IEEE Innovative Smart Grid Technologies-Asia (ISGT-Asia) (pp. 244-249). IEEE.

[77] Ameli, H., Qadrdan, M. and Strbac, G., 2017. Value of gas network infrastructure flexibility in supporting cost effective operation of power systems. Applied Energy, 202, pp.571-580.

[78] Su, Y., Nie, W., Zhou, Y., Tan, M. and Qiao, H., 2017, November. An interval based cost-emissions optimization strategy for gas-electricity integrated energy systems under uncertainty and demand 
response. In 2017 IEEE Conference on Energy Internet and Energy System Integration (EI2) (pp. 1-6). IEEE.

[79] Kou YN, Zheng JH, Li Z, Wu QH. Many-objective optimization for coordinated operation of integrated electricity and gas network. Journal of Modern Power Systems and Clean Energy 2017;5(3);350-63.

[80] Shao C, Ding Y, Wang J, Song Y. Modeling and integration of flexible demand in heat and electricity integrated energy system. IEEE Transactions on Sustainable Energy 2018;9(1);361-70.

[81] An S, Li Q, Gedra TW. Natural gas and electricity optimal power flow. In: 2003 IEEE PES Transmission and Distribution Conference and Exposition (IEEE Cat. No.03CH37495); 2003 Sept 7-12; Dallas, TX, USA.

[82] Chen $Y$, Wang $Y$, Ma J. Multi-objective optimal energy management for the integrated electrical and natural gas network with combined cooling, heat and power plants. Energies 2018;11(4);1-20.

[83] Zhao B, Zlotnik A, Conejo AJ, Sioshansi R, Rudkevich AM. Shadow price-based co-ordination of natural gas and electric power systems. IEEE Transactions on Power Systems 2019;34(3);1942-54.

[84] Devlin J, Li K, Higgins P, Foley A. A novel methodology for analysis of large scale interconnected power and gas systems. In: 2016 13th International Conference on the European Energy Market (EEM); 2016 June 6-9; Porto, Portugal.

[85] Chaudry M, Jenkins N, Strbac G. Multi-time period combined gas and electricity network optimisation. Electric Power Systems Research 2008;78(7);1265-79.

[86] Martinez-Mares A, Fuerte-Esquivel CR. A robust optimization approach for the interdependency analysis of integrated energy systems considering wind power uncertainty. IEEE Transactions on Power Systems 2013;28(4);3964-76.

[87] Zhang R, Jiang T, Li G, Chen H, Li X, Bai L, et al. Day-ahead scheduling of multi-carrier energy systems with multi-type energy storages and wind power. CSEE Journal of Power and Energy Systems 2018; 4(3);283-92.

[88] Chen Y, Xu Y, Li Z, Feng S, Hu C, Hai KL. Optimally coordinated operation of a multi-energy microgrid with coupled electrical and heat networks. In: 2018 International Conference on Power System Technology (POWERCON); 2018 Nov 6-8; Guangzhou, China.

[89] Zhang Y, Le J, Zheng F, Zhang Y, Liu K. Two-stage distributionally robust coordinated scheduling for gas-electricity integrated energy system considering wind power uncertainty and reserve capacity configuration. Renewable Energy 2019;135;122-35.

[90] Fang J, Zeng Q, Ai X, Chen Z, Wen J. Dynamic optimal energy flow in the integrated natural gas and electrical power systems. IEEE Transactions on Sustainable Energy 2018;9(1);188-98.

[91] Zlotnik A, Roald L, Backhaus S, Chertkov M, Andersson G. Coordinated scheduling for interdependent electric power and natural gas infrastructures. IEEE Transactions on Power Systems 2017;32(1);60010.

[92] Acha S, Green TC, Shah N. Impacts of plug-in hybrid vehicles and combined heat and power technologies on electric and gas distribution network losses. In: 2009 IEEE PES/IAS Conference on Sustainable Alternative Energy (SAE); 2009 Sept 28-30; Valencia, Spain. 
[93] Acha S, Green TC, Shah N. Techno-economical tradeoffs from embedded technologies with storage capabilities on electric and gas distribution networks. In: IEEE PES General Meeting; 2010 July 25-29; Providence, RI, USA.

[94] Shabanpour-Haghighi A, Seifi AR. Simultaneous integrated optimal energy flow of electricity, gas, and heat. Energy Conversion and Management 2015;101;579-91.

[95] Unsihuay C, Lima JWM, DeSouza ACZ. Modeling the integrated natural gas and electricity optimal power flow. In: 2007 IEEE Power Engineering Society General Meeting; 2007 June 24-28; Tampa, FL, USA.

[96] He C, Wu L, Liu T, Wei W, Wang C. Co-optimization scheduling of interdependent power and gas systems with electricity and gas uncertainties. Energy 2018;159;1003-15.

[97] Zhang W, Chen J, Li J, Zhang Y. Multi-time scale scheduling of integrated electricity and natural gas system considering the dynamic flow of natural gas. In: 2018 IEEE Innovative Smart Grid Technologies - Asia (ISGT Asia); 2018 May 22-25; Singapore, Singapore.

[98] Xue Y, Gao Y, Li Y, Wen F, Wang K, Huang Y, et al. Optimal coordinated operation of electricity and natural gas distribution networks with power-to-gas facilities. In: 2018 IEEE Innovative Smart Grid Technologies - Asia (ISGT Asia); 2018 May 22-25; Singapore, Singapore.

[99] Pujihatma P, Hadi SP, Sarjiya S. P, Rohmat TA. Integrated gas - electricity network - combined heat and power optimization with associated petroleum and wet gas utilization constraint. International Journal on Advanced Science, Engineering and Information Technology 2018;8(6);2308-14.

[100] Cong H, He Y, Wang X, Jiang C. Robust optimization for improving resilience of integrated energy systems with electricity and natural gas infrastructures. Journal of Modern Power Systems and Clean Energy 2018;6(5);1066-78.

[101] Yan M, Zhang N, Ai X, Shahidehpour M, Kang C, Wen J. Robust two-stage regional-district scheduling of multi-carrier energy systems with a large penetration of wind power. IEEE Transactions on Sustainable Energy 2019;10(3);1227-39.

[102] El-Taweel NA, Khani H, Farag HEZ. Voltage regulation in active power distribution systems integrated with natural gas grids using distributed electric and gas energy resources. International Journal of Electrical Power and Energy Systems 2019;106;561-71.

[103] Wang C, Dong S, Xu S, Yang M, He S, Dong X, et al. Impact of power-to-gas cost characteristics on power-gas-heating integrated system scheduling. IEEE Access 2019;7;17654-62.

[104] Chen Y, Xu Y, Li Z, Feng X. Optimally coordinated dispatch of combined-heat-and-electrical network with demand response. IET Generation, Transmission \& Distribution 2019;13(11);2216-25.

[105] Ceseña EAM, Mancarella P. Energy systems integration in smart districts: Robust optimisation of multi-energy flows in integrated electricity, heat and gas networks. IEEE Transactions on Smart Grid 2019;10(1);1122-31.

[106] Jiandong D, Zhuanting J. Research on improving flexibility of integrated power and gas energy system considering P2G and demand response. In: 2017 IEEE Conference on Energy Internet and Energy System Integration (EI2); 2017 Nov 26-28; Beijing, China. 
[107] Spataru C, Bialek JW. Energy networks: A modelling framework for European optimal cross-border trades. In: 2014 IEEE PES General Meeting; 2014 July 27-31; National Harbor, MD, USA.

[108] Li G, Zhang R, Jiang T, Chen H, Bai L, Li X. Security-constrained bi-level economic dispatch model for integrated natural gas and electricity systems considering wind power and power-to-gas process. Applied Energy 2017;194;696-704.

[109] He C, Wu L, Liu T, Shahidehpour M. Robust co-optimization scheduling of electricity and natural gas systems via ADMM. IEEE Transactions on Sustainable Energy 2017;8(2);658-70.

[110] Ghasemi M, Mashhadi HR, Hejazy A. Importance of gas-fired power plants location in integrated operation of power and natural gas systems: Peak load condition analysis. In: Iranian Conference on Electrical Engineering (ICEE); 2018 May 8-10; Mashhad, Iran.

[111] Liu B, Meng K, Dong ZY, Wei W. Optimal dispatch of coupled electricity and heat system with independent thermal energy storage. IEEE Transactions on Power Systems 2019;34(4);3250-63.

[112] Liu C, Shahidehpour M, Wang J. Coordinated scheduling of electricity and natural gas infrastructures with a transient model for natural gas flow. Chaos 2011;21;025102.

[113] Pambour KA, Erdener BC, Bolado-Lavin R, Dijkema GPJ. Development of a simulation framework for analyzing security of supply in integrated gas and electric power systems. Applied sciences $2017 ; 7 ; 47$.

[114] O'Malley C, Roald L, Kourounis D, Schenk O, Hug G. Security assessment in gas-electric networks. In: 2018 Power Systems Computation Conference (PSCC); 2018 June 11-15; Dublin, Ireland.

[115] Liu J, Sun W, Harrison GP. Optimal low-carbon economic environmental dispatch of hybrid electricity-natural gas energy systems considering P2G. Energies 2019;12;1355.

[116] Clegg S, Mancarella P. Storing renewables in the gas network: modelling of power-to-gas seasonal storage flexibility in low-carbon power systems. IET Generation, Transmission \& Distribution 2016; 10(3);566-75.

[117] Yu X, Zhu G, Wang S, Ding Y. Economic impact of power to gas in integrated electricity and gas system with high wind penetration. In: 2018 IEEE Innovative Smart Grid Technologies - Asia (ISGT Asia); 2018 May 22-25; Singapore, Singapore.

[118] Jiang Y, Guo L. Research on wind power accommodation for an electricity-heat-gas integrated microgrid system with power-to-gas. IEEE Access 2019;7; 87118-26.

[119] Alabdulwahab A, Abusorrah A, Zhang X, Shahidehpour M. Coordination of interdependent natural gas and electricity infrastructures for firming the variability of wind energy in stochastic day-ahead scheduling. IEEE Transactions on Sustainable Energy 2015;6(2);606-15.

[120] Fang X, Cui H, Yuan H, Tan J, Jiang T. Distributionally-robust chance constrained and interval optimization for integrated electricity and natural gas systems optimal power flow with wind uncertainties. Applied Energy 2019;252;113420.

[121] Cao Y, Wei W, Wu L, Mei S, Shahidehpour M, Li Z. Decentralized operation of interdependent power distribution network and district heating network: A market-driven approach. IEEE Transactions on Smart Grid 2019;10(5); 5374-85. 
[122] Wang Y, Wang Y, Huang Y, Yang J, Ma Y, Yu H, et al. Operation optimization of regional integrated energy system based on the modeling of electricity-thermal-natural gas network. Applied Energy 2019;251;113410.

[123] Liu X, Wu J, Jenkins N, Bagdanavicius A. Combined analysis of electricity and heat networks. Applied Energy 2016;162;1238-50.

[124] Lu S, Gu W, Zhou J, Zhang X, Wu C. Coordinated dispatch of multi-energy system with district heating network modeling and solution strategy. Energy 2018;152;358-70.

[125] Costa DCL, Nunes MVA, Vieira JPA, Bezerra UH. Decision tree-based security dispatch application in integrated electric power and natural-gas networks. Electric Power Systems Research 2016;141;44249.

[126] Awad B, Chaudry M, Wu J, Jenkins N. Integrated optimal power flow for electric power and heat in a microgrid. In: CIRED 2009 - The 20th International Conference and Exhibition on Electricity Distribution; 2009 June 8-11; Prague, Czech Republic.

[127] Beccuti G, Demiray T. Operational optimisation for multi-carrier networks. In: 2017 IEEE Manchester PowerTech; 2017 June 18-22; Manchester, UK.

[128] Amirnekooei K, Ardehali MM, Sadri A. Optimal energy pricing for integrated natural gas and electric power network with considerations for techno-economic constraints. Energy 2017;123;693-709.

[129] Martínez-Mares A, Fuerte-Esquivel CR, Wu L, Ortmeyer T. Wind energy impact in fossil fuel management: A multi-energy OPF approach. In: 2012 IEEE Power and Energy Society General Meeting; 2012 July 22-26; San Diego, CA, USA.

[130] Wang X, Bie Z. An MILP-based optimal energy flow of regional multiple energy network. In: 2017 IEEE Conference on Energy Internet and Energy System Integration (EI2); 2017 Nov 26-28; Beijing, China.

[131] Zimmerlin M, Mueller F, Wilferth M, Held L, Suriyah MR, Leibfried T. Mixed integer nonlinear optimization of coupled power and gas distribution network operation. In: 2018 53rd International Universities Power Engineering Conference (UPEC); 2018 Sept 4-7; Glasgow, UK.

[132] Tan $Y$, Wang $X$, Zheng Y. Modeling and daily operation optimization of a distributed energy system considering economic and energy aspects. International Journal of Energy Research 2018;42;347795.

[133] Zhang B, Sun Y, Zhong Y, Shen M. Optimal energy flow of electricity-gas integrated energy system using second-order cone program. In: 2018 Chinese Control And Decision Conference (CCDC); 2018 June 9-11; Shenyang, China.

[134] Mitridati L, Taylor JA. Power systems flexibility from district heating networks. In: 2018 Power Systems Computation Conference (PSCC); 2018 June 11-15; Dublin, Ireland.

[135] Jadidbonab M, Vahid-Pakdel MJ, Seyedi H, Mohammadi-ivatloo B. Stochastic assessment and enhancement of voltage stability in multi carrier energy systems considering wind power. International Journal of Electrical Power \& Energy Systems 2019;106;572-84.

[136] Bao Z, Chen D, Wu L, Guo X. Optimal inter- and intra-hour scheduling of islanded integrated-energy system considering linepack of gas pipelines. Energy 2019;171;326-40. 
[137] Chaudry M, Wu J, Jenkins N. A sequential Monte Carlo model of the combined GB gas and electricity network. Energy Policy 2013;62;473-83.

[138] Cintra CR, Borges CLT, Falcão DM. A simplified operation planning model considering natural gas network and reservoir constraints. In: IEEE PES T\&D 2010; 2010 Apr 19-22; New Orleans, LA, USA.

[139] Zhang R, Jiang T, Li W, Li G, Chen H, Li X. Day-ahead scheduling of integrated electricity and district heating system with an aggregated model of buildings for wind power accommodation. IET Renewable Power Generation 2019;13(6);982-9.

[140] Nikoobakht A, Aghaei J, Fallahzadeh-Abarghouei H, Hemmati R. Flexible co-scheduling of integrated electrical and gas energy networks under continuous and discrete uncertainties. Energy 2019;182;201-10.

[141] Wu QH, Qin YJ, Wu LL, Zheng JH, Li MS, Jing ZX, et al. Optimal operation of integrated energy systems subject to the coupled demand constraints of electricity and natural gas. CSEE Journal of Power and Energy Systems 2019; Early Access Article.

[142] Luo S, Yang L, Zhang X, Chen W, Wang K, Xu Y. A fully linear-constrained optimal electricity-gas flow in an integrated energy system. In: 2018 2nd IEEE Conference on Energy Internet and Energy System Integration (EI2); 2018 Oct 202-22; Beijing, China.

[143] Kou Y, Bie Z, Wang X, Liu F. ADMM-based multiperiod optimal energy flow of a regional integrated multi-energy microgrid. Energy Procedia 2019;159;180-5.

[144] Yang L, Zhao X, Li X, Feng X, Yan W. An MILP-based optimal power and gas flow in electricity-gas coupled networks. Energy Procedia 2019;158;6399-404.

[145] Tan Y, Wang X, Zheng Y. A new modeling and solution method for optimal energy flow in electricitygas integrated energy system. International Journal of Energy Research 2019;43(9);4322-43.

[146] Shao C, Wang X, Shahidehpour M, Wang X, Wang B. An MILP-based optimal power flow in multicarrier energy systems. IEEE Transactions on Sustainable Energy 2017;8(1);239-48.

[147] Liu C, Shahidehpour M, Wang J. Application of augmented lagrangian relaxation to coordinated scheduling of interdependent hydrothermal power and natural gas systems. IET Generation, Transmission \& Distribution 2010;4(12);1314-25.

[148] Wu L, He C, Zhang X, Liu T. Distributionally robust scheduling of integrated gas-electricity systems with demand response. IEEE Transactions on Power Systems 2019;34(5);3791-803.

[149] Shabanpour-Haghighi A, Seifi AR. Effects of district heating networks on optimal energy flow of multi-carrier systems. Renewable and Sustainable Energy Reviews 2016;59;379-87.

[150] Shahidehpour M, Fu Y, Wiedman T. Impact of natural gas infrastructure on electric power systems. Proceedings of the IEEE 2005;93(5);1042-56.

[151] Sayed AR, Wang C, Bi T. Resilient operational strategies for power systems considering the interactions with natural gas systems. Applied Energy 2019;241;548-66.

[152] Wang X, Bie Z, Liu F, Kou Y. Robust dispatch for integrated electricity and natural gas system considering wind power uncertainty. Energy Procedia 2019;159;130-5. 
[153] Bai L, Li F, Jiang T, Jia H. Robust scheduling for wind integrated energy systems considering gas pipeline and power transmission $\mathrm{N}-1$ contingencies. IEEE Transactions on Power Systems 2017;32(2);1582-4.

[154] Saldarriaga-C CA, Salazar H. Security of the Colombian energy supply the need for liquefied natural gas regasification terminals for power and natural gas sectors. Energy 2016;100;349-62.

[155] Liu C, Shahidehpour M, Fu Y, Li Z. Security-constrained unit commitment with natural gas transmission constraints. IEEE Transactions on Power Systems 2009;24(3);1523-36.

[156] Alabdulwahab A, Abusorrah A, Zhang X, Shahidehpour M. Stochastic security-constrained scheduling of coordinated electricity and natural gas infrastructures. IEEE Systems Journal 2017;11(3);1674-83.

[157] Ding T, Xu Y, Wei W, Wu L. Energy flow optimization for integrated power-gas generation and transmission systems. IEEE Transactions on Industrial Informatics 2019;Early Access Article.

[158] Saldarriaga CA, Hincapié RA, Salazar H. A holistic approach for planning natural gas and electricity distribution networks. IEEE Transactions on Power Systems 2013;28(4);4052-63.

[159] Odetayo B, MacCormack J, Rosehart WD, Zareipour H. A sequential planning approach for distributed generation and natural gas networks. Energy 2017;127;428-37.

[160] Saldarriaga CA, Hincapie RA, Salazar H. An integrated expansion planning model of electric and natural gas distribution systems considering demand uncertainty. In: 2015 IEEE Power \& Energy Society General Meeting; 2015 July 26-30; Denver, CO, USA.

[161] Rees MT, Wu J, Jenkins N, Abeysekera M. Carbon constrained design of energy infrastructure for new build schemes. Applied Energy 2014;113;1220-34.

[162] Chaudry M, Jenkins N, Qadrdan M, Wu J. Combined gas and electricity network expansion planning. Applied Energy 2014;113;1171-87.

[163] Wang D, Qiu J, Meng K, Gao X, Dong Z. Coordinated expansion co-planning of integrated gas and power systems. Journal of Modern Power Systems and Clean Energy 2017;5(3);314-25.

[164] Zhao B, Conejo AJ, Sioshansi R. Coordinated expansion planning of natural gas and electric power systems. IEEE Transactions on Power Systems 2018;33(3);3064-75.

[165] Qadrdan M, Chaudry M, Wu J, Jenkins N, Ekanayake J. Impact of a large penetration of wind generation on the GB gas network. Energy Policy 2010;38(10);5684-95.

[166] Odetayo B, MacCormack J, Rosehart WD, Zareipour H. Integrated planning of natural gas and electricity distribution networks with the presence of distributed natural gas fired generators. In: 2016 IEEE Power and Energy Society General Meeting (PESGM); 2016 July 17-21; Boston, MA, USA.

[167] Qiu J, Dong ZY, Zhao JH, Meng K, Zheng Y, Hill DJ. Low carbon oriented expansion planning of integrated gas and power systems. IEEE Transactions on Power Systems 2015;30(2);1035-46.

[168] Huang G, Wen F, Salam MA, Dong Z, Zheng Y, Zhang R. Optimal collaborative expansion planning of integrated electrical and natural gas energy systems. In: 2016 IEEE Innovative Smart Grid Technologies - Asia (ISGT-Asia); 2016 Nov 28-Dec 1; Melbourne, VIC, Australia. 
[169] Odetayo B, Kazemi M, MacCormack J, Rosehart WD, Zareipour H, Seifi AR. A chance constrained programming approach to the integrated planning of electric power generation, natural gas network and storage. IEEE Transactions on Power Systems 2018;33(6);6883-93.

[170] Zhang Y, Hu Y, Ma J, Bie Z. A mixed-integer linear programming approach to security-constrained cooptimization expansion planning of natural gas and electricity transmission systems. IEEE Transactions on Power Systems 2018;33(6);6368-78.

[171] Khaligh V, Buygi MO, Moghaddam AA, Guerrero JM. Integrated expansion planning of gas-electricity system: A case study in Iran. In: 2018 International Conference on Smart Energy Systems and Technologies (SEST); 2018 Sept 10-12; Sevilla, Spain.

[172] Odetayo B, MacCormack J, Rosehart WD, Zareipour H, Seifi AR. Integrated planning of natural gas and electric power systems. International Journal of Electrical Power \& Energy Systems 2018;103;593-602.

[173] Ding T, Hu Y, Bie Z. Multi-stage stochastic programming with nonanticipativity constraints for expansion of combined power and natural gas systems. IEEE Transactions on Power Systems 2018; $33(1) ; 317-28$.

[174] Gao Y, Wen F, Wang K, Huang Y, Xue Y. Optimal collaborative planning with demand side management in integrated gas-electricity energy systems. In: 2018 IEEE Power \& Energy Society General Meeting (PESGM); 2018 Aug 5-10; Portland, OR, USA.

[175] Wang X, Bie Z, Liu F. Optimal expansion planning of multi-energy generations and natural gas storages in integrated energy system. In: 2018 IEEE Power \& Energy Society General Meeting (PESGM); 2018 Aug 5-10; Portland, OR, USA.

[176] Saldarriaga-Cortés C, Salazar H, Moreno R, Jiménez-Estévez G. Stochastic planning of electricity and gas networks: An asynchronous column generation approach. Applied Energy 2019;233-234;106577.

[177] Ojeda-Esteybar DM, Rubio-Barros RG, Vargas A. Integrated operational planning of hydrothermal power and natural gas systems with large scale storages. Journal of Modern Power Systems and Clean Energy 2017;5(3);299-313.

[178] Zeng Q, Zhang B, Fang J, Chen Z. A bi-level programming for multistage co-expansion planning of the integrated gas and electricity system. Applied Energy 2017;200;192-203.

[179] Odetayo B, MacCormack J, Rosehart WD, Zareipour H. A chance constrained programming approach to integrated planning of distributed power generation and natural gas network. Electric Power Systems Research 2017;151;197-207.

[180] Khaligh V, OloomiBuygi M, AnvariMoghaddam A, Guerrero JM. Leader-follower approach to gaselectricity expansion planning problem. In: 2018 IEEE International Conference on Environment and Electrical Engineering and 2018 IEEE Industrial and Commercial Power Systems Europe (EEEIC / I\&CPS Europe); 2018 June 12-15; Palermo, Italy.

[181] Qiu J, Yang H, Dong ZY, Zhao JH, Meng K, Luo FJ, et al. A linear programming approach to expansion co-planning in gas and electricity markets. IEEE Transactions on Power Systems 2016;31(5);3594606. 
[182] Unsihuay-Vila C, Marangon-Lima JW, DeSouza ACZ, Perez-Arriaga IJ, Balestrassi PP. A model to longterm, multiarea, multistage, and integrated expansion planning of electricity and natural gas systems. IEEE Transactions on Power Systems 2010;25(2);1154-68.

[183] Odetayo B, MacCormack J, Rosehart WD, Zareipour H. A real option assessment of flexibilities in the integrated planning of natural gas distribution network and distributed natural gas-fired power generations. Energy 2018;143;257-72.

[184] Sánchez CB, Bent R, Backhaus S, Blumsack S, Hijazi H, VanHentenryck P. Convex optimization for joint expansion planning of natural gas and power systems. In: 2016 49th Hawaii International Conference on System Sciences (HICSS); 2016 Jan 5-8; Koloa, HI, USA.

[185] Saldarriaga-Cortés CA, Salazar H, Moreno R, Jiménez-Estévez G. Integrated planning of electricity and natural gas systems under uncertain hydro inflows: A multi-objetive approach. In: 2017 IEEE Power \& Energy Society General Meeting; 2017 July 16-20; Chicago, IL, USA.

[186] Shao C, Shahidehpour M, Wang X, Wang X, Wang B. Integrated planning of electricity and natural gas transportation systems for enhancing the power grid resilience. IEEE Transactions on Power Systems 2017;32(6);4418-29.

[187] Esteybar DMO, Rubio-Barros RG, Vargas A. Large storage facilities valuation in integrated planning of natural gas and power systems. In: 2016 IEEE PES Transmission \& Distribution Conference and Exposition-Latin America (PES T\&D-LA); 2016 Sept 20-24; Morelia, Mexico.

[188] Barati F, Seifi H, Sepasian MS, Nateghi A, Shafie-khah M, Catalão JPS. Multi-period integrated framework of generation, transmission, and natural gas grid expansion planning for large-scale systems. IEEE Transactions on Power Systems 2015;30(5);2527-37.

[189] Zhang X, Shahidehpour M, Alabdulwahab A, Abusorrah A. Optimal expansion planning of energy hub with multiple energy infrastructures. IEEE Transactions on Smart Grid 2015;6(5);2302-11.

[190] He C, Wu L, Liu T, Bie Z. Robust co-optimization planning of interdependent electricity and natural gas systems with a joint $\mathrm{N}-1$ and probabilistic reliability criterion. IEEE Transactions on Power Systems 2018;33(2);2140-54.

[191] Zhang X, Shahidehpour M, Alabdulwahab AS, Abusorrah A. Security-constrained co-optimization planning of electricity and natural gas transportation infrastructures. IEEE Transactions on Power Systems 2015;30(6);2984-93.

[192] Hejeejo R, Qiu J, Mirzaeva G. Optimal expansion planning of coordinated multi-energy sources under the impact of a decentralised grid and gas system. In: 2018 IEEE Power \& Energy Society General Meeting (PESGM); 2018 Aug 5-10; Portland, OR, USA.

[193] Jing X, Shiju W, Yiming H, Ke X, Kai Y, Chongbo S. Research on optimal planning method for the safe and efficient electric - gas multi energy system. In: 2018 China International Conference on Electricity Distribution (CICED); 2018 Sept 17-19; Tianjin, China.

[194] Chen H, Meng K, Qiu J, Dong ZY. Expansion co-planning of integrated electricity-heat-gas networks in district energy systems. In: 2018 IEEE Power \& Energy Society General Meeting (PESGM); 2018 Aug 5-10; Portland, OR, USA. 
[195] Qiu J, Dong ZY, Zhao JH, Meng K, Tian H, Wong KP. Expansion co-planning with uncertainties in a coupled energy market. In: 2014 IEEE PES General Meeting, Conference \& Exposition; 2014 July 2731; National Harbor, MD, USA.

[196] Qiu J, Dong ZY, Zhao JH, Xu Y, Zheng Y, Li C, et al. Multi-stage flexible expansion co-planning under uncertainties in a combined electricity and gas market. IEEE Transactions on Power Systems 2015;30(4);2119-29.

[197] Ghasemi H, Aghaei J, Gharehpetian GB, Safdarian A. MILP model for integrated expansion planning of multi-carrier active energy systems. IET Generation, Transmission \& Distribution 2019;13(7);117789.

[198] Zhou H, Zheng J, Wu QH, Zhou XX. Co-planning and feasibility assessment of an integrated energy system embedded with power-to-gas plants. In: 2019 IEEE PES GTD Grand International Conference and Exposition Asia (GTD Asia); 2019 March 19-23; Bangkok, Thailand.

[199] Samsatli S, Samsatli NJ. A multi-objective MILP model for the design and operation of future integrated multi-vector energy networks capturing detailed spatio-temporal dependencies. Applied Energy 2018;220;893-920.

[200] Diagoupis TD, Andrianesis PE, Dialynas EN. A planning approach for reducing the impact of natural gas network on electricity markets. Applied Energy 2016;175;189-98.

[201] Torres J, Symko-Davies M. Energy Systems Integration Facility (ESIF) 2018. National Renewable Energy Laboratory (NREL); 2019 Jan. Report No.: NREL/BR-5C00-73025.

[202] Jamasb T, Llorca M. Energy systems integration: economics of a new paradigm. Economics of Energy \& Environmental Policy 2019;8(2);7-28.

[203] Sadeghi $H$, Rashidinejad M, Moeini-Aghtaie M, Abdollahi A. The energy hub: An extensive survey on the state-of-the-art. Applied Thermal Engineering 2019;161; 114071.

[204] Mohammadi M, Noorollahi Y, Mohammadi-ivatloo B, Yousefi H. Energy hub: From a model to a concept - A review. Renewable and Sustainable Energy Reviews 2017;80;1512-1527.

[205] Lopes AMG. Implementation of the Hardy-Cross method for the solution of piping networks. Computer Applications in Engineering Education 2004;12(2);117-125. 